\title{
Roadmap for additive manufacturing of HAYNES® $282 ®$ superalloy by laser beam powder bed fusion (PBF-LB) technology
}

\author{
Robert Otto $^{\mathrm{a}, \mathrm{e}, 1, *}$, Vegard Brøtan ${ }^{\mathrm{b}, 1}$, Patricia A. Carvalho ${ }^{\mathrm{c}}$, Magnus Reiersen ${ }^{\mathrm{d}}$, Joachim S. Graff ${ }^{\mathrm{c}}$, \\ Martin F. Sunding ${ }^{\text {, }}$, Olav Åsebø Berg ${ }^{\text {b }}$, Spyros Diplas ${ }^{\text {, }}$, Amin S. Azar ${ }^{\mathrm{c}, 1}$ \\ a Siemens AG, Technology, Germany \\ b SINTEF Manufacturing, Trondheim, Norway \\ c SINTEF Industry, Oslo, Norway \\ d University of Oslo (UiO), Oslo, Norway \\ e Norwegian University of Science and Technology (NTNU), Department of Mechanical and Industrial Engineering, Trondheim, Norway
}

\section{H I G H L I G H T S}

- A comprehensive approach was introduced for investigating the root cause of material failure under AM conditions. - HAYNES ${ }^{2} 282 \circledR(\mathrm{H} 282)$ superalloy was investigated as a new material for laser beam powder bed fusion (PBF-LB) technology.

- Precipitation- and residual stress control under recurrent thermal cycles are key to success in PBF-LB processing of $\mathrm{H} 282$.

- Heated build platform to $300{ }^{\circ} \mathrm{C}$ and novel scan strategy results in low porosity and micro-crack free material.

- Hot isostatic pressing recrystallizes the microstructure, eliminates porosity and heals the micro-cracks.

\section{A R T I C L E I N F O}

\section{Article history:}

Received 8 January 2021

Received in revised form 8 March 2021

Accepted 11 March 2021

Available online 13 March 2021

\section{Keywords:}

Haynes 282 (H282)

Powder Bed Fusion (PBF)

Additive Manufacturing (AM)

Superalloy

Micro-crack

\section{G R A P H I C A L A B S T R A C T}

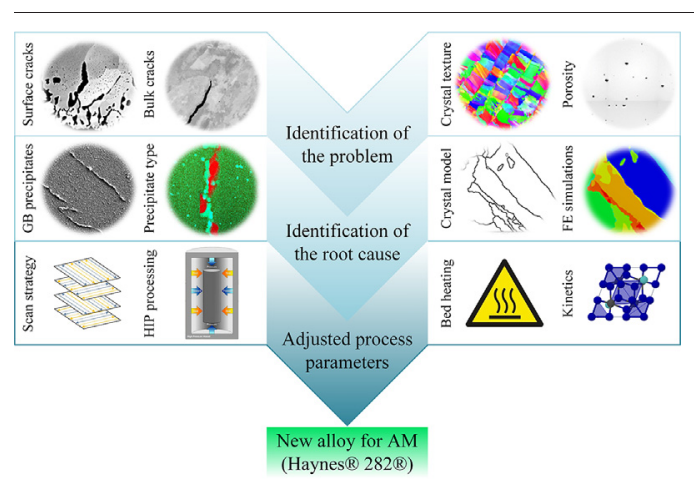

\begin{abstract}
A B S T R A C T
Although various alloy systems have been explored for additive manufacturing (AM) during the past decade, introducing a new alloy remains a challenging task. Most of the materials require iterative builds, for investigating numerous parameters and determining a viable and repeatable process window.

Among the challenging yet highly demanded materials, Haynes 282 superalloy was chosen. It was initially processed through conventional density cube approach, by varying the process parameters for each processed cube. Although the relative densities of the initial builds were not dramatically low, micro-cracks were present in all of them, mostly evolved on a selective number of grain boundaries and spanning only across a single laser path. Detailed modelling and advanced characterization techniques were employed to understand the root cause and cracking mechanism. It was found that the grain boundary precipitates are responsible for crack initiation, amid stress gradient across the grain boundary due to the adjacent grain orientations. Therefore, the failure mechanism is determined as ductility-dip cracking. Based on the findings, a new process window was defined using elevated temperature and novel scanning strategy. No cracks were observed under the modified processing window, meaning that the material can reliably be processed by laser beam powder bed fusion (PBF-LB).
\end{abstract}

(C) 2021 The Authors. Published by Elsevier Ltd. This is an open access article under the CC BY license (http:// creativecommons.org/licenses/by/4.0/).

\footnotetext{
* Corresponding author at: Otto-Hahn-Ring 6, 81739 Munich, Germany.

E-mail addresses: robert-otto@siemens.com, robert.otto@ntnu.no (R. Otto).

${ }^{1}$ Authors that contributed equally to this work.
} 


\section{Introduction}

\subsection{Background}

Additive Manufacturing (AM) is known to enable new design concepts and processing approaches for various modern materials. In general terms, AM comprises a group of processing steps, where successive layers of material are added (layer-by-layer) and fused by a concentrated heat source [1]. In this study, Laser Beam Powder Bed Fusion (PBF-LB) technology is in focus. This process has several trademarked names, e.g., Laser Cusing, Selective Laser Melting, Direct Metal Laser Melting, etc. The addition of layers is challenging for the structural integrity of the final product due to the recursive thermal cycles and associated solidification phenomena. This limits material choices as most of the engineering alloys cannot tolerate such processing conditions without appropriate modifications.

Therefore, research efforts associated with this specific AM technology focus on alloy optimisation. In this context, a fundamental understanding of the origin of problems that prohibit use of specific industrial materials is required. In this study, we present the roadmap for processing the $\mathrm{H} 282$ superalloy using PBF-LB technology.

There are numerous successful attempts using this alloy in various types of AM. Unocic et al. [2], processed H282 using electron beam melting (EBM). They have reported that by controlling the beam scanning velocity, beam current, hatch spacing, line order, and beam focus, they could process a crack- and porosity-free material. The boldest process parameter in their study was to apply an extremely high bed heating temperature, around $1000{ }^{\circ} \mathrm{C}$. In addition, they employed three sets of beam process parameters and they varied focus offset, hatch spacing, line orders and speed function for comparison purposes. They found that the best set of processing conditions relied on highest speed function and lowest hatch spacing, corresponding to a high volumetric energy density.

Kirka et al. [3], have also reported a successful development of EBM process parameters, such as speed function, hatch spacing, line order, and focus offset, for the H282 alloy in collaboration with Haynes International.

Ramakrishnan et al. [4], investigated the effect of process parameters on the properties of $\mathrm{H} 282$ using laser metal deposition (LMD). Although AM processing took place without any substrate pre-heating, they observed heat accumulation in the substrate or previously deposited layers as a result of continuous deposition, the processed materials were also free of porosity, cracks, and incomplete fusion. Heat treatment was performed on the basis of thermodynamic considerations of the alloy. They observed anisotropic texture and although the microstructural features were comparable to the findings by Unocic et al., the average size of the $\gamma^{\prime}$ precipitates was nevertheless almost a tenth of that in materials processed by EBM.

In a recent study by Deshpande et al. [5], H282 was processed by PBF-LB. They used only one set of process parameters and they employed post-process hot isostatic pressing (HIP). Although the reported as-built microstructures showed no apparent cracks, there was no discussion on the relative density and possible presence of the cracks in the material. The major focus was on the subsequent HIPing process to claim that it improves the quality by healing the cracks and closing the pores. They also showed that HIPing promotes complete recrystallization and makes the microstructure less anisotropic. Moreover, they discussed how the heating conditions promote precipitation and where and how the precipitates form.

In an early study reported by researchers involved in the present study [6], the challenges of processing the H282 alloy were delineated. Despite the lack of success in finding suitable process parameters, results from 84 fabricated test cubes using 36 settings have shown that the process parameter alone has a tremendous effect on the formation of the pores and cracks in the material. No bed heating was applied for the processing of the reported samples in this early study.

In laser powder bed fusion processing of $\gamma^{\prime}$-strengthened materials. In general, the processability of these alloys Adegoke et al. [7], reviewed the recent developments deteriorates as the $\mathrm{Al}+\mathrm{Ti}$ content increases. Four mechanisms lead to structural failure in $\gamma$ '-strengthened materials. Al and Ti expand the solidification range resulting in solidification (hot) cracking. However, the $\mathrm{Al}$ and Ti content needs to be above $4.5 \mathrm{wt}$ $\%$ for this phenomenon to dominate [8] and this is hardly the case for $\mathrm{H} 282$. Another reported phenomenon is liquation cracking owing to melting of the grain boundary constituents in the solidified material. The third failure mechanism is strain age cracking that is associated with the post-processing heat treatments. The fourth reported failure phenomenon is called ductility-dip cracking which is associated to the relief of high stress concentration at the grain boundaries due to dilatation and grain boundary migration [9]. The validity of these phenomena on the cracks evolved in $\mathrm{H} 282$ will be discussed in detail in this article.

In this line of research, we have further investigated the root causes of crack formation in the material by combining advanced characterization and modelling. Numerous samples under various processing conditions were investigated for their microstructure using scanning electron microscopy (SEM), electron backscattered diffraction (EBSD), scanning transmission electron microscopy (STEM), light microscopy (LM) and series of relative density characterizations. In addition, the hardness values of the material before and after heat treatment were reported.

\subsection{Material: the HAYNES® $282 \circledast$ superalloy}

Modern high-temperature applications like in gas turbines for the aerospace and energy sectors would not operate safely without utilising Ni-based superalloys having outstanding creep resistant at elevated temperatures. Moreover, Ni-based superalloys exhibit high temperature oxidation resistance, which is also important for highperformance applications in those sectors [10].

Ni-based superalloys are strengthened by solid-solution and precipitation hardening brough by two main types of precipitates: gamma-prime $\left(\gamma^{\prime}\right)$ and gamma-double-prime $\left(\gamma^{\prime \prime}\right)$ [11]. The facecentre cubic (fcc) gamma-prime has a very small lattice misfit of $0.13 \%$ with the austenitic nickel matrix $(\gamma)$. Therefore, it became the most important precipitate enabling high-temperature stability [12,13].

The precipitation characteristics are determined by the chemical composition of the alloy and the heat treatment practice. In particular, it is known that a certain ratio of $\mathrm{Al}$ and Ti promotes the formation of $\gamma^{\prime}$ precipitates [14-16], while Nb contributes to formation of $\gamma$ ". The majority of $\gamma^{\prime}$ forms during the specific aging heat treatment, leading to higher strength. However, it is known that precipitation-hardened superalloys are prone to cracking during or after welding, respectively known as hot cracking and strain-aged cracking. Increased presence of $\gamma^{\prime}$ precipitates in the microstructure is also associated with processing failures [17]. As the conventional processing window turns narrower, near-net-shape fabrication processes, like casting, powder metallurgy and AM, become more applicable [12].

Introduced in 2005, the $\mathrm{H} 282$ alloy was designed to achieve balance between processability and strength, provided by $\gamma^{\prime}$ precipitation [15]. Although several studies have reported the processability of $\mathrm{H} 282$ by 
Table 1

Nominal chemical composition of H282 and IN718 in wt\%.

\begin{tabular}{|c|c|c|c|c|c|c|c|c|c|c|c|c|}
\hline & $\mathrm{Ni}$ & $\mathrm{Cr}$ & Co & Mo & $\mathrm{Ti}$ & Al & $\mathrm{Fe}$ & Mn & $\mathbf{S i}$ & C & B & Nb \\
\hline H282 & $57^{\mathrm{a}}$ & 20 & 10 & 8.5 & 2.1 & 1.5 & $1.5 b$ & 0.3 & $1.5^{\mathrm{b}}$ & 0.06 & 0.005 & - \\
\hline IN718 & $50-55^{a}$ & $17-21$ & $1^{\mathrm{b}}$ & $2.8-3.3$ & $0.65-1.15$ & $0.2-0.8$ & B & $0.35^{\mathrm{b}}$ & $0.35^{\mathrm{b}}$ & $0.08^{\mathrm{b}}$ & 0.006 & $4.75-5.5$ \\
\hline
\end{tabular}

a As balance.

b Maximum B: Balance.

conventional means like welding [18-27] and casting [28], this alloy is fairly new to AM.

The similarity in melting point, laser wavelength absorption and solidification phenomena instigated us to start the optimization procedure by adopting the successful set of parameters developed for Inconel 718 (IN718). Table 1 shows the chemical composition of the H282 compared with the compositional range for IN718.

As discussed in detail in this study, the driving factor for crack formation is a certain combination of heat input and pre-heating conditions. Therefore, alternative scan strategies and process heating can be applied to improve control over the heat input.

\section{Experimental procedure}

\subsection{Feedstock}

The feedstock used for this study was supplied by Praxair Surface Technologies (Indianapolis, USA) with a particle size within the range of 11-45 $\mu \mathrm{m}$. The target and actual compositions of the used H282 powder are compared in Table 2.

The samples in the study have been produced using pristine (virgin) powder, which was analysed for particle size distribution (PSD) and morphology, absorption properties of the laser wavelength and elemental mapping prior to the production of samples.

The powder PSD and morphology was determined using a Malvern Morphologi G3 microscope. A number of 94,220 particles of $\mathrm{H} 282$ were imaged for PSD and morphology analysis. The advantage of the technique is that single particles can be analysed and, therefore, the contribution of each particle to the distribution is the same, so that particles of any size have equally important "weighting" contribution.

\subsection{Sample design and orientation}

The coordinate system used in this work follows the ISO/ASTM 52900 definitions. Consequently, the $x$-direction is positive towards the right-hand side of the machine. The coater, located on a positive $x$ position, moves towards negative $x$ while depositing the layers [1]. The build platform consisted of a round IN718 plate inserted into a larger square steel plate adaption.

Cubic samples were designed with dimensions of $5 \times 5 \times 5 \mathrm{~mm}$ or $10 \times 10 \times 10 \mathrm{~mm}$. All samples were designed with a $5 \mathrm{~mm}$ thick support structure at the bottom to minimize contact between the consolidated cubes and the build plate. The support structure had $0.5 \mathrm{~mm}$ squared hatching lines parallel to the samples surface with triangle tips on the top to hold the part in place.

The samples were numbered in correlation to their manufacturingparameter-set and were produced with a $5 \mathrm{~mm}$ distance from each other on the build plate. Independent from their actual order on the build plate, the sample formation has been rotated $10^{\circ}$ anti-clockwise around the centre of the build-plate to avoid simultaneous contact between the coater-blade and the long line of sample array.

\subsection{Manufacturing parameters, scan strategies and post processing}

All samples were fabricated on a Concept Laser M2 using a $200 \mathrm{~W}$ Yb:YAG fibre laser with a wavelength of 1050-1250 nm. Nitrogen was used as shielding gas during fabrication, as the influence of inert gases on the material has been proven insignificant [29].

Three builds were conducted, with the parameters listed in Table 3. The process parameters for these builds were selected from a previous study [6], focusing on the highest achieved relative densities. To distinguish different parameter sets, the volumetric energy density $E_{v o l}$ has been chosen as the figure of merit. $E_{v o l}=P /$ $(v \cdot t \cdot h)$, where $P$ is the laser power, $v$ is the scan velocity, $t$ is the layer thickness and $h$ is the hatch spacing. Build 2 was planned to increase the bed heating to $300{ }^{\circ} \mathrm{C}$, running on the sample process parameters as for build 1 .

Scan strategies applied in the previous study, namely, the standard and modified island strategy [6] have been complemented with two additional strategies. These strategies are developed by the authors in order to achieve a better understanding of the effect of heat distribution in the processed samples. With variations in scanning chronology of the laser paths, the strategies 1212 and 1234 were designed as additional possibilities to control the energy input by the laser. The scan strategies will be explained and visualized in the following subsections:

\subsubsection{Standard island strategy}

A standard island is usually a square area of $5 \mathrm{~mm}$ side length, whereby the laser is traveling either in $x$ - or $y$-directions of the machine, independent of the parts orientation.

Fig. 1a shows the general schematic visualization of the islandstrategy, when Concept Laser machines are used. There are several laser-paths per island, which follow a parallel raster pattern at the end of each path. As the laser is not turned off while changing the path, the laser movement to the reverse headed laser path results in shorter orthogonal connections. The orientation of the parallel laser paths rotates every layer around by $90^{\circ}$. In addition, the part's outer contour is also scanned. Nevertheless, islands of consecutive layers are not placed exactly above each other as an attempt to break the through-thickness crystallographic texture in the solidified material.

\subsubsection{Modified island strategy}

The pattern of the modified island strategy is similar to the original island strategy presented in Fig. 1a. However, the modified island is aligned with the edges of the cubic parts. The modified islands are either squares of $5 \mathrm{~mm}$ or $10 \mathrm{~mm}$ side length ( $5 \mathrm{~mm}$ and $10 \mathrm{~mm}$ cubic samples, respectively) and the laser paths are parallel to the edges of the part and not the $x$ - and $y$-directions of the machine.

Table 2

Chemical composition of $\mathrm{H} 282$ powder compared to the nominal values in wt\%.

\begin{tabular}{llllllllllll}
\hline & Ni & Cr & Co & Mo & Ti & Al & Fe & Mn & Si & C & B \\
\hline Target & $57^{\mathrm{a}}$ & 20 & 10 & 8.5 & 2.1 & 1.5 & $1.5^{\mathrm{b}}$ & 0.3 & $1.5^{\mathrm{b}}$ & 0.06 & 0.005 \\
Actual & 56.94 & 19.48 & 10.14 & 8.49 & 2.11 & 1.56 & 1 & 0.15 & 0.08 & 0.06 & 0.004 \\
\hline
\end{tabular}

\footnotetext{
a As balance.
}

b Maximum. 
Table 3

Processing parameter build 1 and 2 . Build 2 was performed at $300^{\circ} \mathrm{C}$.

\begin{tabular}{|c|c|c|c|c|c|}
\hline Scan Strategy & $\mathrm{P}[\mathrm{W}]$ & $\mathrm{v}[\mathrm{mm} / \mathrm{s}]$ & $\mathrm{t}[\mathrm{mm}]$ & $\mathrm{h}[\mathrm{mm}]$ & $\mathrm{E}_{\mathrm{vol}}\left[\mathrm{J} / \mathrm{mm}^{3}\right]$ \\
\hline Standard island & 180 & 620,625 & 0.03 & 0.105 & $91.43 ; 92.17$ \\
\hline Modified island & 180 & $600,605,620,625$ & 0.03 & 0.105 & $91.43-95.24$ \\
\hline 1212-strategy & 180 & 560,620 & 0.03 & $0.095,0.105$ & $(101.02-112.78)^{0.095} ; 91.43-102.04$ \\
\hline 1234-strategy & 180 & 560,620 & 0.03 & $0.095,0.105$ & $(101.02-112.78)^{0.095} ; 91.43-102.04$ \\
\hline
\end{tabular}

0.095: values for hatch spacing $0.095 \mathrm{~mm}$.

a

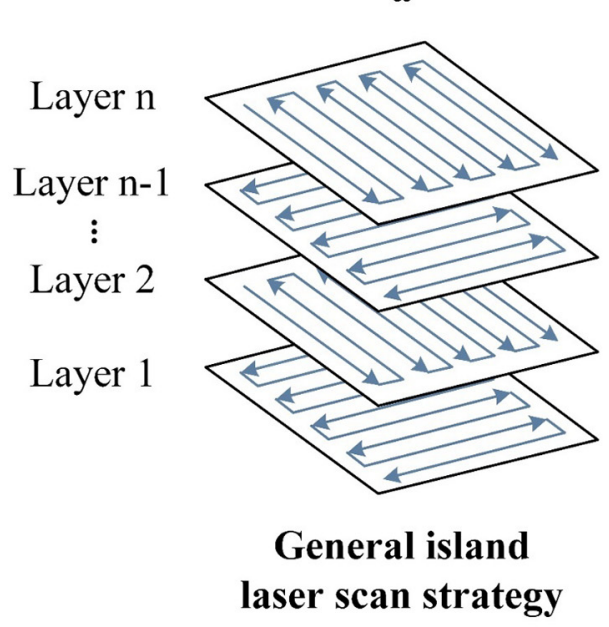

b

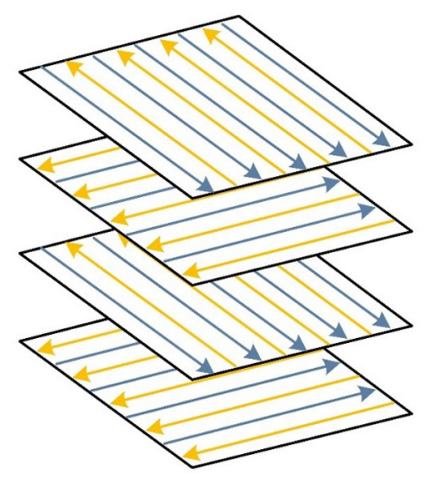

1212 laser scan strategy

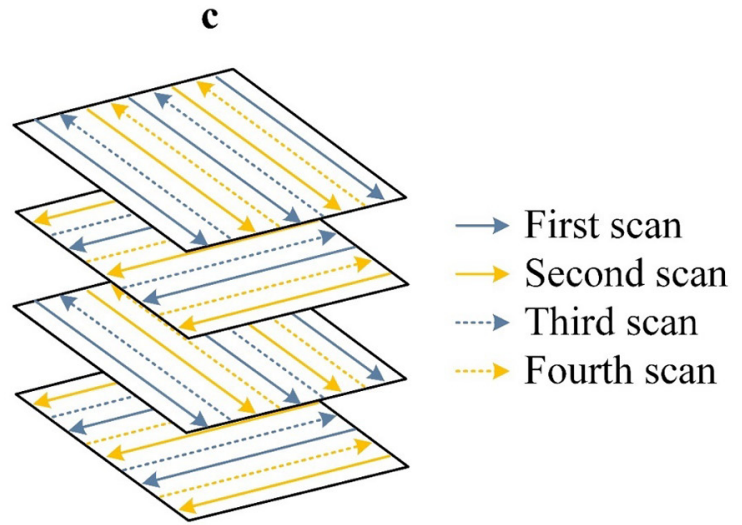

1234 laser scan strategy

Fig. 1. Laser scan strategies.

\subsubsection{2-strategy}

Similar to the island strategies, the laser scanning pattern of the new strategies consists also of parallel paths, and the scanning direction changes from path to path. In this strategy, instead of planning for one connected laser-path-line over the given area, the laser paths are separately grouped. Thus, no short orthogonal connection is present, as the paths are fused separately from each other. The groups of laser paths are defined to design the scanning chronology of the laser, as every path of one group must be scanned prior to the next group. Two sequent groups are designed to have a reverse direction of the associated laser paths and a reverse direction of their paths' scan chronology. The contour line is fused subsequently.

Fig. 1b shows the pattern of the designed 1212-strategy. It includes two alternating laser path groups with changing laser scanning direction, respectively. As explained above and regarding the scan chronology, first all paths of group 1 (e.g., blue) are scanned before the paths of group 2 (e.g., yellow). Thereby, the distance between the successively scanned laser path doubles in comparison to the above-described island strategies. The paths of consecutive layers are rotated by $90^{\circ}$.

\subsubsection{4 - strategy}

The 1234-strategy follows the principles of the above described1212strategy, with the difference that it includes four instead of two laser path groups. Group related paths are alternating their scan direction as counting up, and sequenced groups have a reverse scan chronology. As shown in Fig. 1c, that leads to a distance for consecutively scanned laser paths being up to four times as large as compared to the island-based strategies.

The samples including support structure were heat treated after their removal from the build plate. The standard heat treatment for welded H282, including full-solution-annealing, was chosen. The thermal cycle is delineated in Table 4.

\subsection{Characterization, modelling, and mechanical tests}

Cubes have been prepared by standard metallographic procedures. Dark field and bright field images were acquired by light microscopy to investigate the porosity and the presence of micro-cracks in the samples. For the densitometry studies, the images were analysed by an ImageJ macro (grayscale Otsu thresholding [30]).

The effect of processing parameters on surface roughness was investigated by white light interferometry (WLI) using a Veeco Wyko NT9800 instrument. WLI measurements were performed only on the crack-free sample set.

The microstructure of the materials was investigated by SEM in combination with EBSD for orientation mapping using an FEI NOVA NanoSEM650 instrument equipped with an Oxford Instruments Nordlys EBSD system. An area of $400 \times 348 \mu \mathrm{m}^{2}$ was scanned with a step size of $0.25 \mu \mathrm{m}$ around an arbitrary micro-crack region, to accumulate 139,200 datapoints (pixels) for further analyses. Unless otherwise expressed, all microstructural investigations were performed on cross sections parallel to the build plate. Wherever needed, the material was electro-polished to reveal the microstructural features. Standard steel electro-polishing parameters and electrolytes from Struers were used.

In order to investigate the root cause of the cracking phenomena, multi-physics thermally induced crystal-elasticity modelling was performed. The input to the model was the EBSD orientation mapping from an arbitrarily observed cracked region. Fig. 2a shows the band

Table 4

Heat treatment parameters.

\begin{tabular}{ll}
\hline Solution-Annealing & Age Hardening \\
\hline $1135{ }^{\circ} \mathrm{C} / 2 \mathrm{~h} / \mathrm{WQ}$ & $1010{ }^{\circ} \mathrm{C} / 2 \mathrm{~h} / \mathrm{AC}+788^{\circ} \mathrm{C} / 8 \mathrm{~h} / \mathrm{AC}$
\end{tabular}

WQ: Water Quenching AC: Air Cooling. 
Band contrast
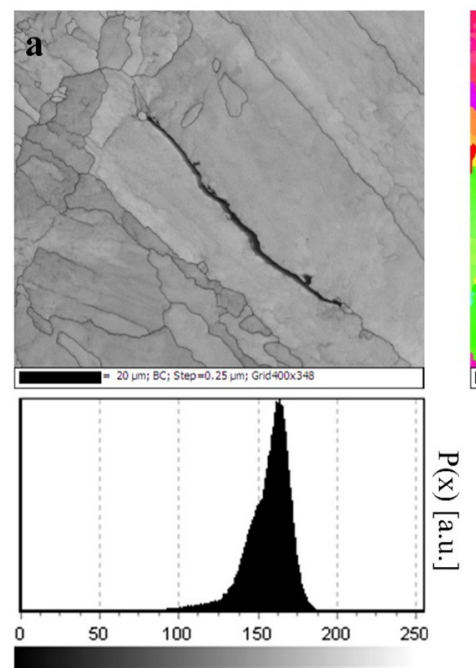

IPF-Z original
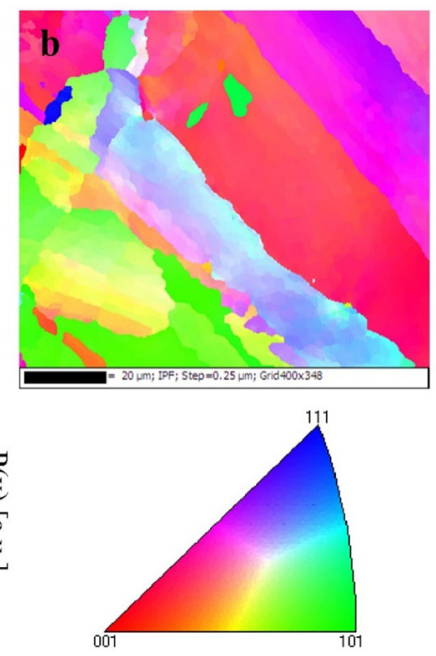

Averaged orientation
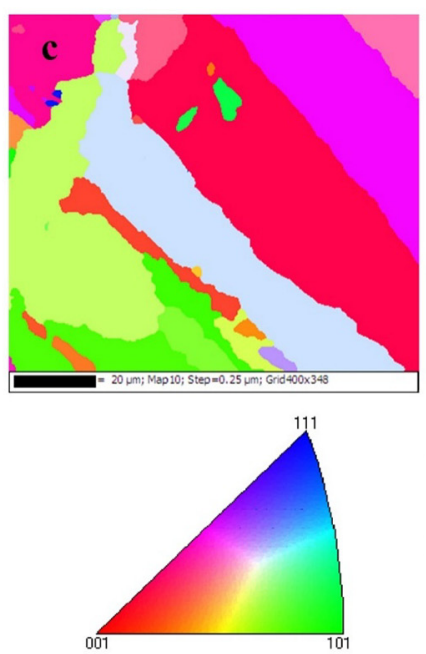

Grain boundaries
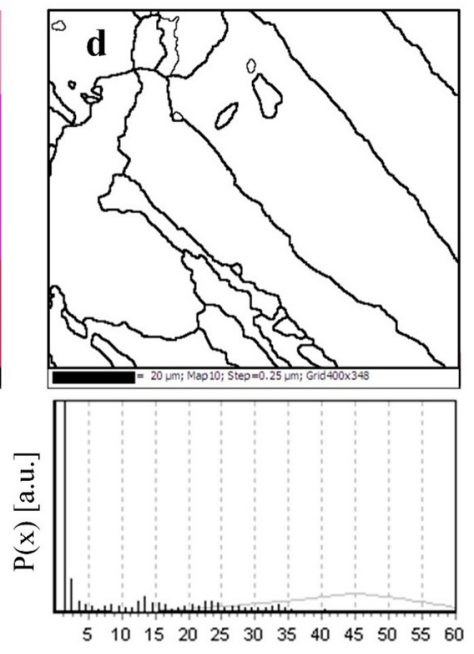

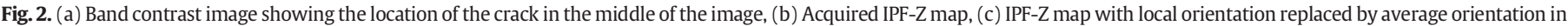
each grain and (d) Extracted grain boundary map with reported orientation frequency.

contrast of the region around a selected crack. The obtained map was cleaned with relevant parameters and grain crystallographic orientation was identified. Fig. 2b shows the inverse pole figure (IPF-Z) map of the region. In order to simplify the effect of grain orientation, gradients within a single grain were flattened out, and the average orientation of all pixels of that specific grain was replaced instead. Fig. 2c shows the average orientation for each grain. The Euler angles of each grain were subsequently recorded in order to be used in the elastic plasticity modelling.

Thereafter, the grain boundary map was extracted (Fig. 2d), and an identical CAD model was created from the EBSD map. Fig. 3 shows the CAD model established in Abaqus. The thickness of the model was assumed to be equal to the layer thickness and the grains were as thick as the fused layer. Each grain was segmented (sectioned) to introduce the unique Euler angles defining the anisotropy of that specific grain.

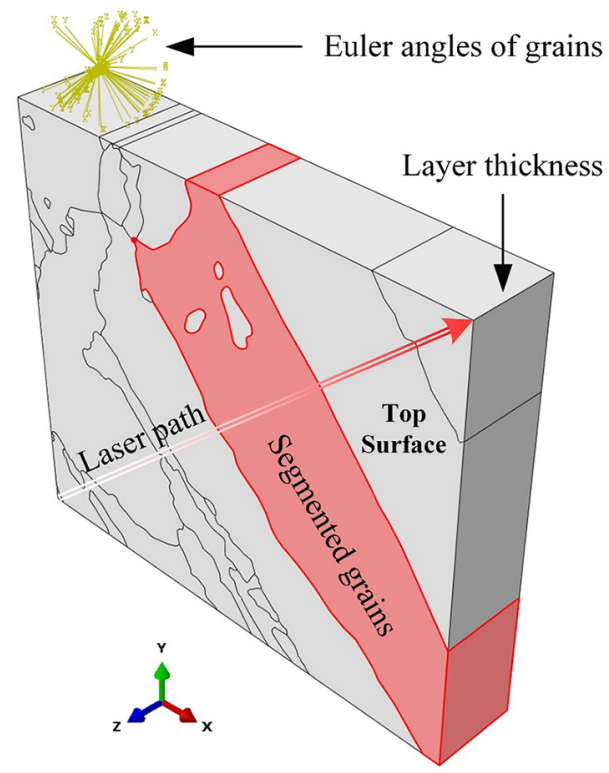

Fig. 3. CAD model of the EBSD acquisition area.
Following the establishment of the property model, the boundary conditions were applied. Similar to the experiments, the laser is traveling diagonally starting from the bottom left corner towards the upper right corner. Upon solidification, apart from the top surface all free surfaces are anchored by the surrounding materials and movements stop. In this manner, the effect of shrinkage on the grains and their relative interaction can be captured. The elastic constants of IN718 were used due to their relative similarity to the $\mathrm{H} 282$ properties. In general, we aimed to determine the relative orientation correlation of the grains under the given processing conditions and the deviation from the employed mechanical properties had minor effect on this objective. Table 5 shows the applied transverse orthotropic elastic stiffness constants of the IN718 at two different temperatures, assuming linear interpolation between the given temperatures. The data is collected from the literature [31-33].

Linear elasticity of the orthotropic material was defined by providing the nine independent elastic stiffness parameters, as functions of temperature. In this case the stress-strain relations are of the form:

$$
\begin{aligned}
\left\{\begin{array}{l}
\sigma_{11} \\
\sigma_{22} \\
\sigma_{33} \\
\sigma_{12} \\
\sigma_{13} \\
\sigma_{23}
\end{array}\right\} & {\left[\begin{array}{cccccc}
D_{1111} & D_{1122} & D_{1133} & 0 & 0 & 0 \\
& D_{2222} & D_{2233} & 0 & 0 & 0 \\
& & D_{3333} & 0 & 0 & 0 \\
\text { sym } & & D_{1212} & 0 & 0 \\
\varepsilon_{11} \\
\varepsilon_{22} \\
\varepsilon_{33} \\
\gamma_{12} \\
\gamma_{13} \\
\gamma_{23}
\end{array}\right\} }
\end{aligned}
$$

Table 5

Orthotropic elastic constants of pure nickel at two different temperatures (values in GPa).

\begin{tabular}{llllllllll}
\hline $\mathbf{D}_{\mathbf{1 1 1 1}}$ & $\mathbf{D}_{\mathbf{1 1 2 2}}$ & $\mathbf{D}_{\mathbf{2 2 2 2}}$ & $\mathbf{D}_{\mathbf{1 1 3 3}}$ & $\mathbf{D}_{\mathbf{2 2 3 3}}$ & $\mathbf{D}_{\mathbf{3 3 3 3}}$ & $\mathbf{D}_{\mathbf{1 2 1 2}}$ & $\mathbf{D}_{\mathbf{1 3 1 3}}$ & $\mathbf{D}_{\mathbf{2 3 2 3}}$ & Temp. \\
\hline 275.6 & 125.8 & 274.5 & 152.3 & 153.4 & 248.0 & 107.6 & 106.4 & 68.0 & $25{ }^{\circ} \mathrm{C}$ \\
154.3 & 70.4 & 153.7 & 85.2 & 85.9 & 138.8 & 60.2 & 59.5 & 38.0 & $1375{ }^{\circ} \mathrm{C}$ \\
\hline
\end{tabular}


where $\sigma$ is the stress element and $\varepsilon$ is the strain element. For an orthotropic material, the engineering constants define the D matrix as:

$$
\begin{aligned}
& D_{1111}=E_{1}\left(1-\nu_{23} \nu_{32}\right) \Upsilon \\
& D_{2222}=E_{2}\left(1-\nu_{13} \nu_{31}\right) \Upsilon \\
& D_{3333}=E_{3}\left(1-\nu_{12} \nu_{21}\right) \Upsilon \\
& D_{1122}=E_{1}\left(\nu_{21}+\nu_{31} \nu_{23}\right) \Upsilon=E_{2}\left(\nu_{12}+\nu_{32} \nu_{13}\right) \Upsilon \\
& D_{1133}=E_{1}\left(\nu_{31}+\nu_{21} \nu_{32}\right) \Upsilon=E_{3}\left(\nu_{13}+\nu_{12} \nu_{23}\right) \Upsilon \\
& D_{2233}=E_{2}\left(\nu_{32}+\nu_{12} \nu_{31}\right) \Upsilon=E_{3}\left(\nu_{23}+\nu_{21} \nu_{13}\right) \Upsilon \\
& D_{1212}=G_{12} \\
& D_{1313}=G_{13}, \\
& D_{2323}=G_{23},
\end{aligned}
$$

where $E$ is the elastic modulus, $v$ is the Poisson's ratio, $G$ is the shear modulus and $r$ is defined as:

$\Upsilon=\frac{1}{1-\nu_{12} \nu_{21}-\nu_{23} \nu_{32}-\nu_{31} \nu_{13}-2 \nu_{21} \nu_{32} \nu_{13}}$

A local orientation is defined by the angle $\alpha$, adapted from the EBSD maps of each grain. Thus, in the cross-section directions the stress-strain relations are as follows:

$\left\{\begin{array}{l}\sigma \\ \tau_{1} \\ \tau_{2}\end{array}\right\}=\left[\begin{array}{ccc}E & 0 & 0 \\ & G_{1}(\cos \alpha)^{2}+G_{2}(\sin \alpha)^{2} & \left(G_{1}-G_{2}\right) \cos \alpha \sin \alpha \\ & \operatorname{sym} & G_{1}(\sin \alpha)^{2}+G_{2}(\cos \alpha)^{2}\end{array}\right]\left\{\begin{array}{c}\varepsilon \\ \gamma_{1} \\ \gamma_{2}\end{array}\right\}$

where $\sigma$ represents the stress and $\tau_{1}$ and $\tau_{2}$ represent two shear stresses. More detailed description of the finite element formulation can be found in [34].

The Vickers hardness of the processed cubes was measured for the three different parameter sets, with and without heat treatment. A $1 \mathrm{~N}$ force was used to measure hardness across the vertical and horizontal layers. Samples with relatively high count of pores and cracks were further consolidated using hot isostatic pressing (HIP). Fig. 4 illustrates the HIP process parameters.

Selected samples were investigated by annular bright-field (ABF) and high-angle annular dark field (HAADF) STEM. The microscopy work was performed with a DCOR Cs probe-corrected FEI Titan G2 60-300 instrument with $0.08 \mathrm{~nm}$ of nominal spatial resolution. Chemical information was obtained by x-ray energy dispersive spectroscopy

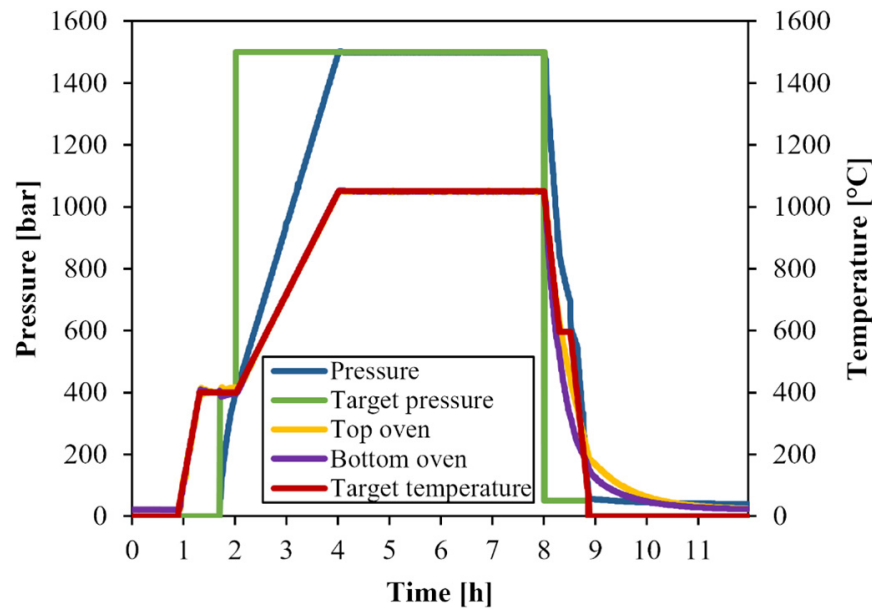

Fig. 4. Selected HIP process parameters for the H282 samples. Yellow, purple, and red temperature lines are overlapping, showing that the target temperature is reached and there is no significant gradient inside the chamber.

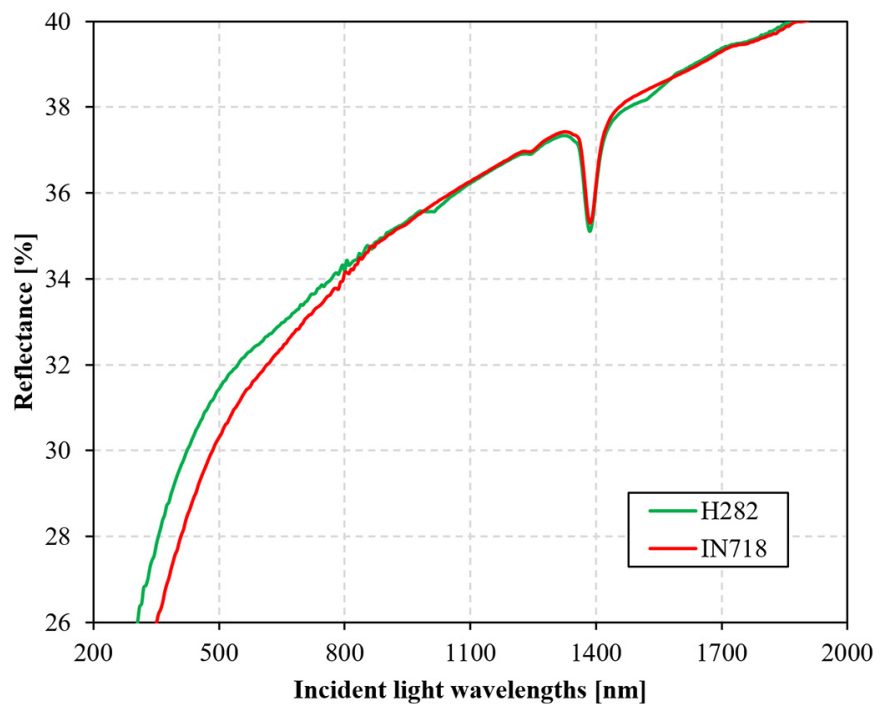

Fig. 5. Reflectance of H282 and IN718.

(EDS) with a Bruker SuperX EDS system, comprising four silicon drift detectors. STEM samples were prepared using focused ion beam with $\mathrm{Ga}+$ ions accelerated at $30 \mathrm{kV}$ on a FEI Helios G4 dual beam system (Gatan Inc). The crystallographic orientations between the phases were investigated using crystallographic data retrieved from literature (see Table 7).

In the following section, the results of the various studies are presented and discussed individually and comparatively.

\section{Results and discussion}

\subsection{Powder analysis}

The reflectance of the $\mathrm{H} 282$ feedstock was analysed and compared to that of IN718 standard Concept Laser powder with comparable size distribution and Fig. 5 displays the results. The reflectance of the $1030 \mathrm{~nm}$ laser used in these experiments is similar and approximately $36 \%$. Assuming the transmittance to be negligible, the rest of the incident photons can be absorbed by the feedstock, causing a rise in temperature and eventual local melting. This supports the decision of using the processing parameters of IN718 as a starting point for the current study.

Fig. 6 displays results of PSD and morphology. The analysed feedstock shows acceptable circularity, as $90 \%$ of the powder is within 0.875 in perimeter/diameter (circularity) value. The peak of the size distribution curve for the $\mathrm{H} 282$ feedstock is at about $35 \mu \mathrm{m}$ as shown in Fig. 6. The powder size distribution (PSD) affects powder packing density and flowability, which in turn affects the surface finish and density of the final components.

\subsection{Simulations}

In the constructed model, the material was heated to the peak temperature (just below the liquidus temperature) and subsequently cooled down to room temperature at a high cooling rate and under the defined boundary conditions. The whole cycle lasted $230 \mu$ s. The thermal cycle duration was calculated based on the average laser speed divided by the length scale of the model. Upon cooling, the model was constrained in all directions (except the top free surface) to impose elastic deformation in the solidified grains. Since the elastic property of each grain was defined based on the orientation maps, the residual stress, displacement, and shear of each grain will be different from the adjacent one, resulting in inhomogeneous distributions across 

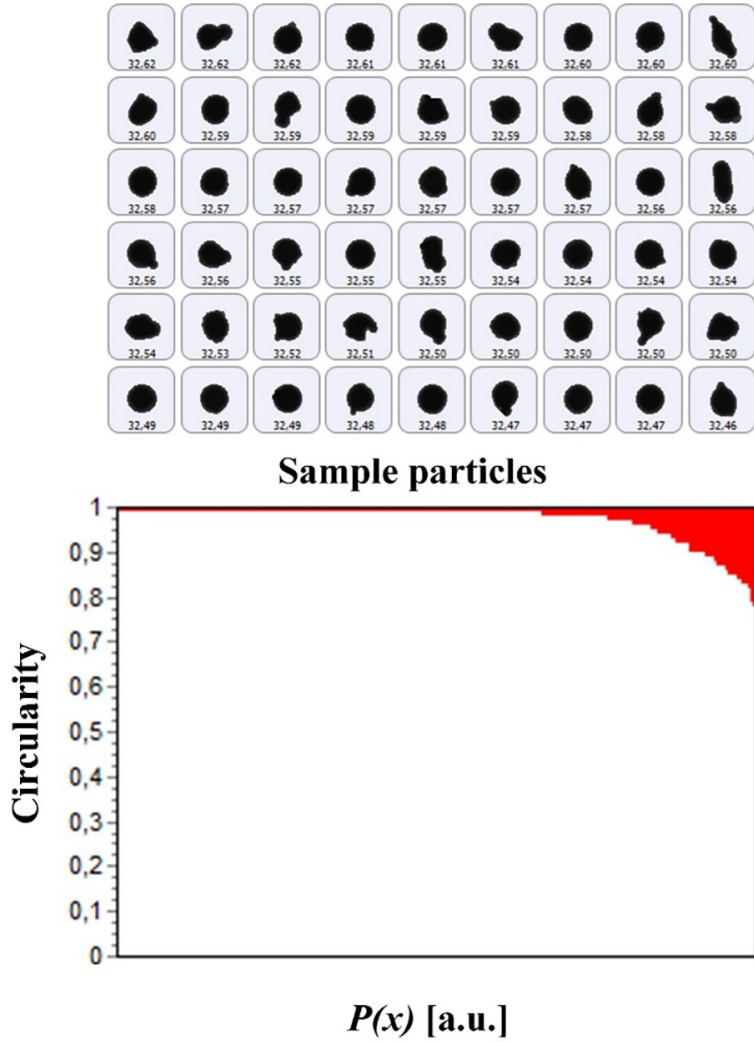

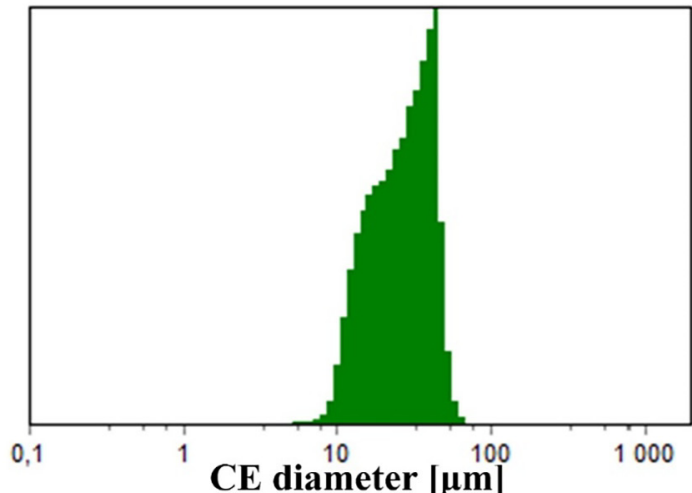

$\frac{\overparen{2}}{\frac{2}{2}}$

Fig. 6. Powder size and distribution $P(x)$ of the supplied pristine $\mathrm{H} 282$

Post-thermal cycle residual stress at $\mathrm{RT}$
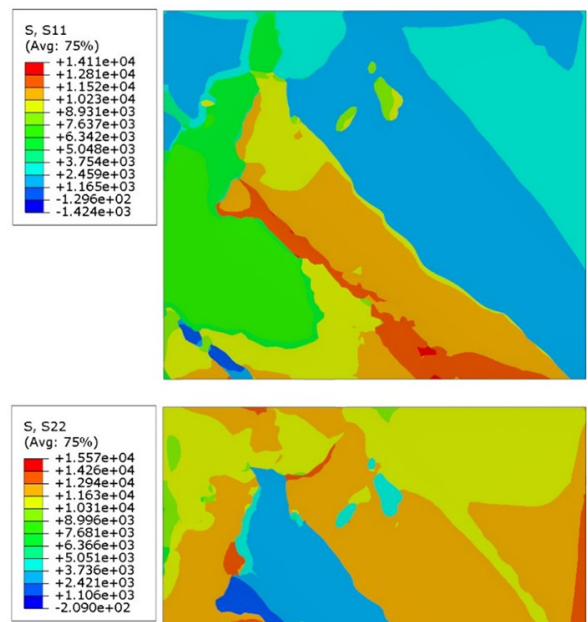

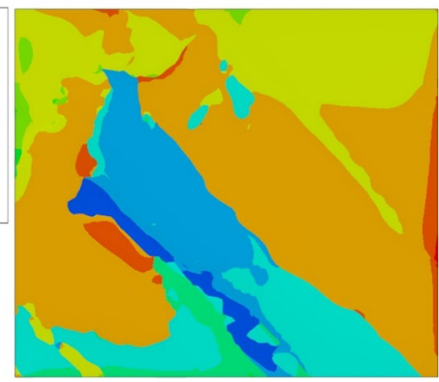

Post-thermal cycle elastic residual stress at RT
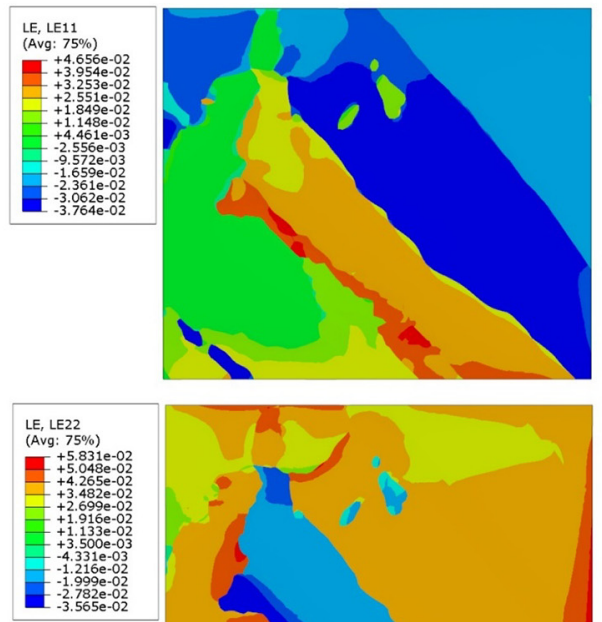

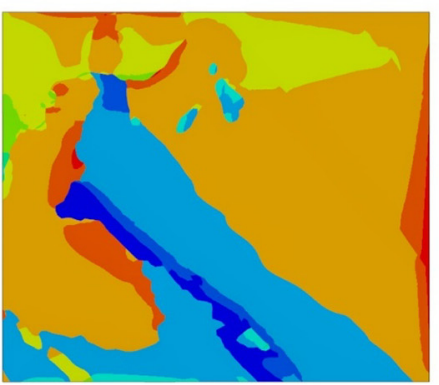

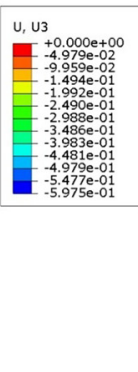

Residual shear and displacement at RT
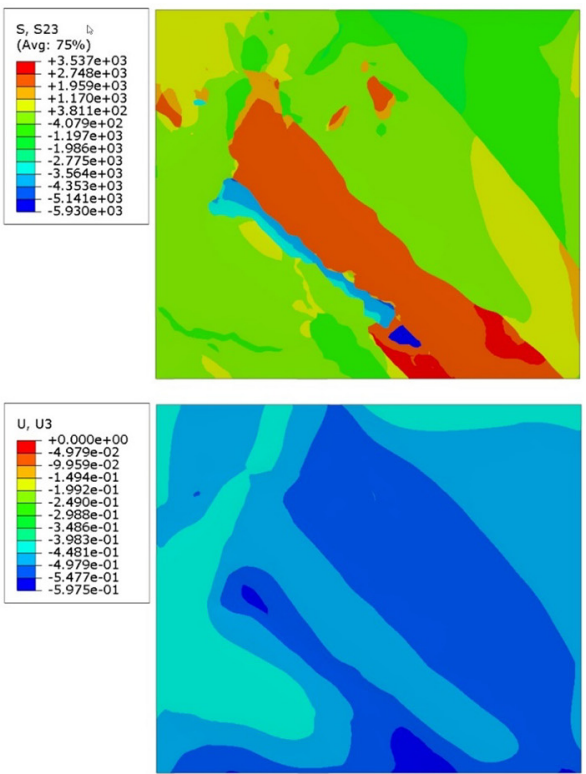

Fig. 7. Selected results of the crystal elasticity simulations under given AM thermal cycle conditions. 

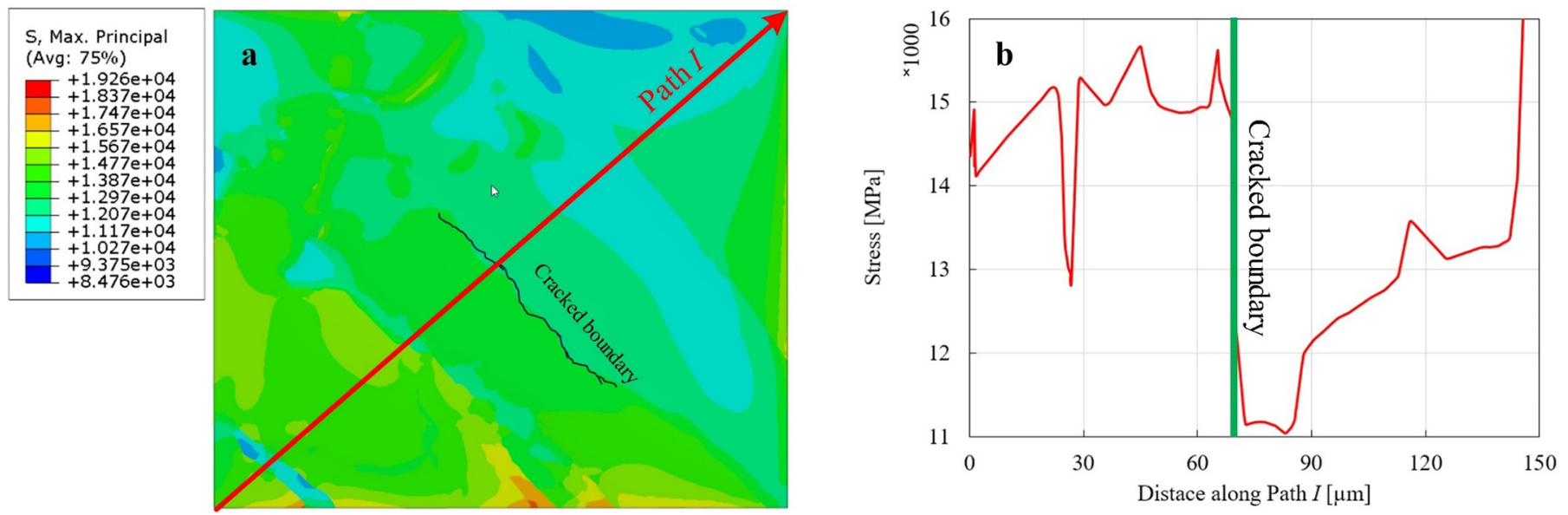

Fig. 8. (a) Max. principal stress after the thermal cycle, (b) the value of max. Principal stress along path $I$ in (a).

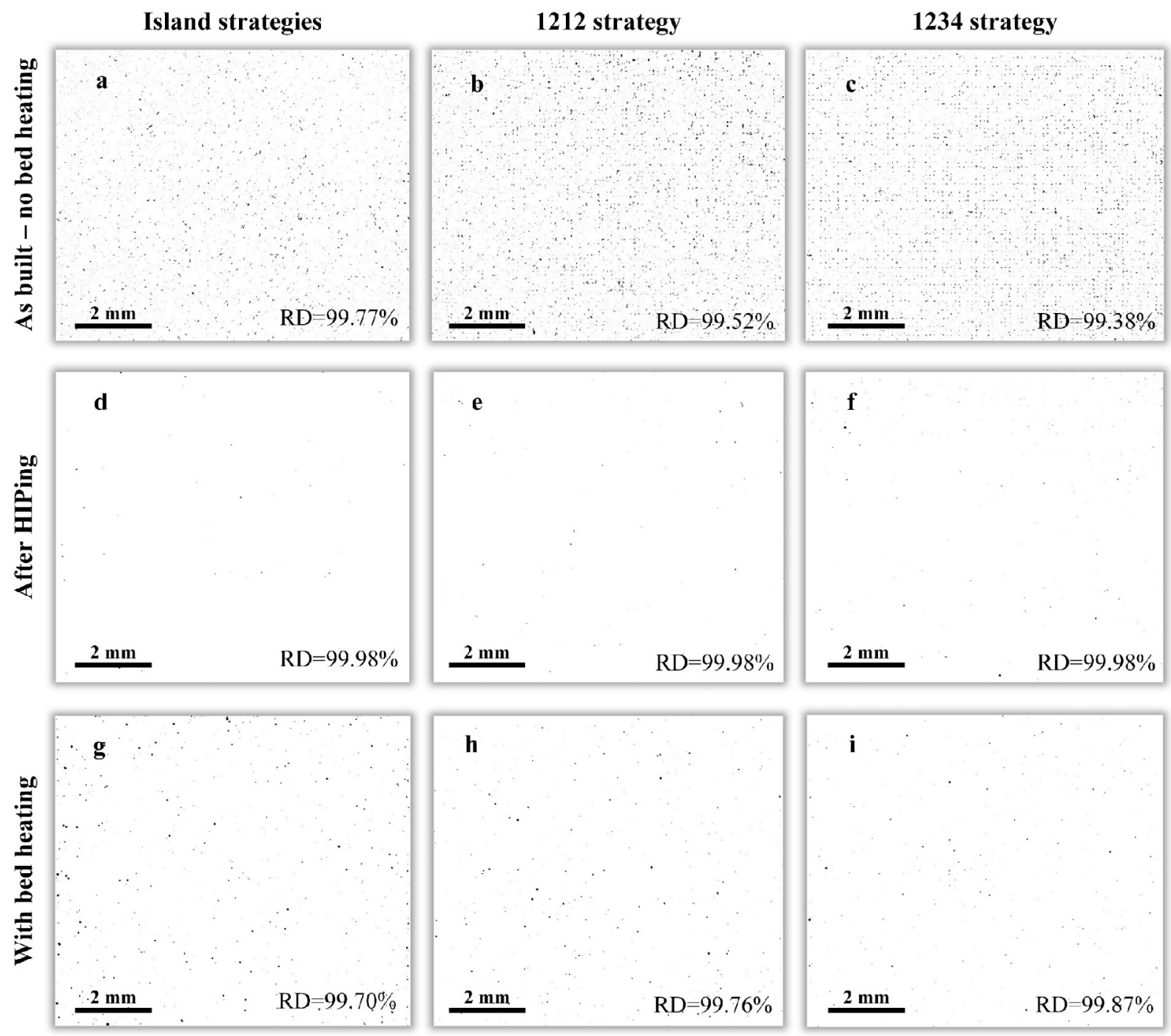

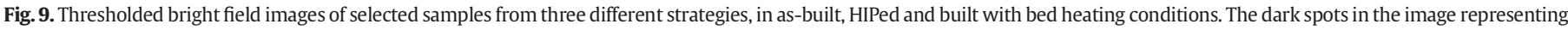
micro-cracks dominance $(\mathrm{a}-\mathrm{c})$ or porosity dominance $(\mathrm{d}-\mathrm{i})$. 
the model. Fig. 7 shows various components of the total residual stress (RS), elastic residual stress, and residual shear and displacement of the model. As shown, the conditions of the applied boundary with respect to the grain orientations has created different RS values in the given region. Comparison of the $S_{11}$ and $S_{22}$ components of the RS, shows that the grains adjacent to the cracked grain boundary exhibit at least one order of magnitude difference in the computed stress values. This means that the crack region suffers from high residual stress difference and subsequently local stress gradients. Fig. 8a shows the distribution of the maximum principal stress after the applied thermal cycle. Fig. 8b illustrates the values of the max. Principal stress along the depicted path. As show, the values across the cracked boundary vary as much as $40 \%$, causing a large mismatch in the state of stress distribution. Therefore, abrupt changes in the stress state caused by the different grain orientations under a given thermal cycle are responsible for nucleation of cracks at the grain boundary. Such mechanism is in line with the requirements of ductility-dip cracking that was reviewed earlier in the introduction section.

Controlling the adverse effects of ductility-dip cracking requires restricted dilatation of the grains in the solidified material throughout the imposed thermal cycle. One of the best solutions to achieve this is to increase the baseline temperature of the build. By doing so, the cooling temperature range between the peak and the elevated baseline temperatures will be shortened, avoiding large and abrupt shrinkage in the system. Thus, the proposed remedy against grain boundary cracking is to elevate the build temperature by applying bed heating during the process. The results of this attempt will be presented later in this section.

\subsection{Porosity and cracks}

Typical examples of the porosity and micro-cracking distributions of one sample from each strategy type are shown in Fig. 9. The images were taken on a light optical microscope at high magnification and were stitched together to create an overview of the entire sampled area. Thresholding was applied to the images to capture the defects as black features on a white background. The as-built samples without bed heating show higher population of micro-cracks, most of which are perpendicular to the laser tracks. Among the applied toolpath, the 1234 strategy shows the highest number of arrayed micro-cracks, resulting in the lowest measured relative density (RD) among all the samples. As described before, the 1212 and 1234 strategies skip the most immediate laser path, allowing the material to cool locally. Once those skipped tracks are exposed to high temperatures, the conditions for dilatation and cracking appear to be maximized. The temperature difference between the adjacent lines becomes higher in these novel strategies, causing high magnitudes of local dilatation and subsequent cracking.

The severely cracked samples shown in Fig. 9 (a - c) were HIPed with the processing conditions described in Fig. 4. The results after HIPing of all those samples, regardless of the initial relative density, appear to be consistent, showing a relative density of $99.98 \%$. In-depth microstructure investigation of the HIPed samples revealed that all micro-cracks were healed, and the porosity was reduced significantly. This observation suggests that the selected HIPing parameters were successful in closing the pores and cracks. The HIPing process has brought about significant changes in the microstructure of the material as will be discussed in Section 3.6.

Nevertheless, HIPing is another processing step that imposes extra costs to the entire AM value-chain. Moreover, some strict end-users do not approve any processing step with defects, even if it can be rectified in the subsequent steps.

Thus, we investigated an alternative option to eliminate the cracking risk in the laser processing step by applying bed heating at $300^{\circ} \mathrm{C}$. Fig. 9 $(g-i)$ shows the measured relative density of the samples processed with simultaneous bed heating. The most prominent result of this approach was that the underlaying micro-cracking was eliminated. This was manifested by microstructural investigations of cross-sectional areas, which revealed absence of micro-cracks in the sample (see Fig. 13). However, some porosity was present in the samples and in all cases the relative density of the samples was above $99.7 \%$. Among the applied laser scan strategies, the 1234 strategy yields the highest relative density (99.87\%), as opposed to the effect of this toolpath under "no bed-heating" conditions.
Roughness parameters (free surface perpendicular to the build plate)

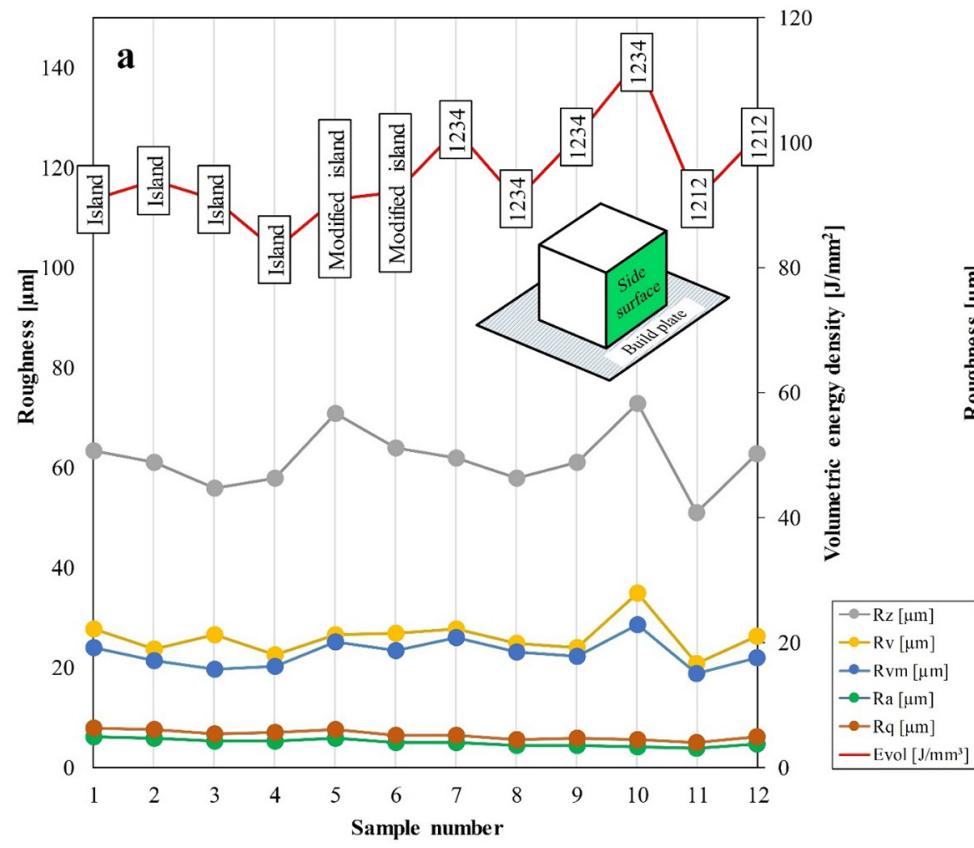

Roughness parameters (free surface parallel to the build plate)

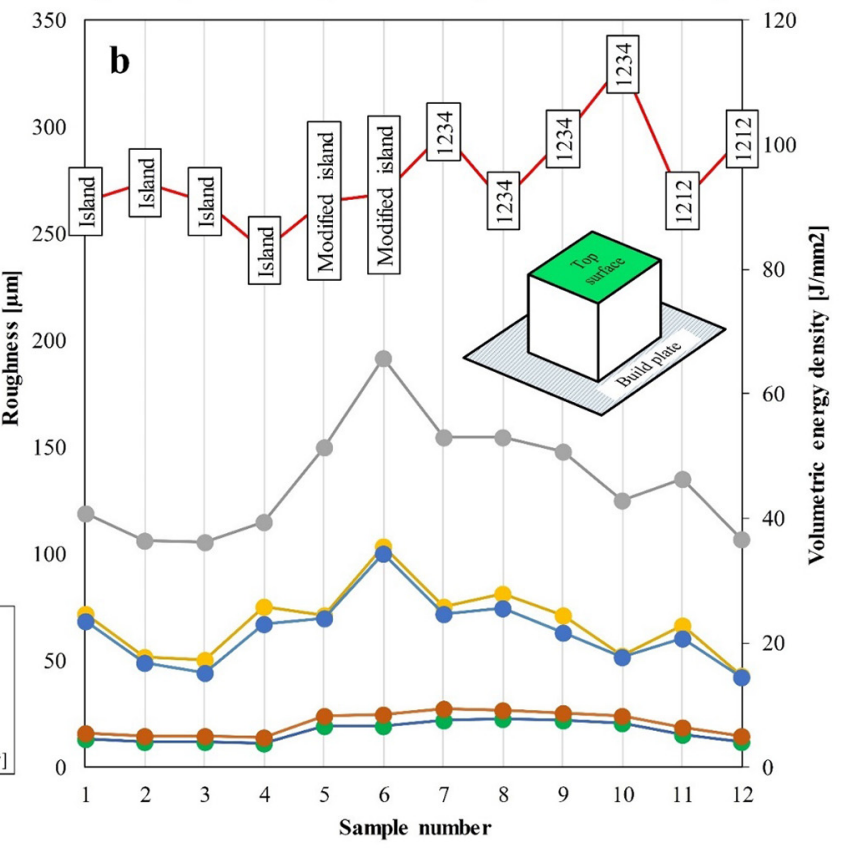

Fig. 10. Surface roughness values acquired from the side (a) and top (b) surfaces for 12 samples, with their corresponding volumetric energy density and laser scan strategies. 
The evolved porosity may be eliminated through implementation of higher bed heating (as applied by Unocic et al. [2], for the EBM process), improved feedstock quality (e.g., by avoiding exposure to air and moisture), improved laser parameters (e.g., higher laser power or volumetric energy density) or a single step HIPing.

\subsection{Surface roughness}

Fig. 10a shows roughness values from measurements on an arbitrary surface perpendicular to the build plate, and Fig. 10b shows values of the same samples, resulting from measurements on the top surface. The effect of processing parameters on surface roughness of additive manufactured samples is a well-established topic. Wang et al. [35], investigated the surface roughness of a Ti-6Al- $4 \mathrm{~V}$ material processed by EBM and concluded that different settings affect the as-built topography on the sample. In 2017, Tian et al. [36], investigated the influence of laser powder bed fusion processing parameters on a Hastalloy-X material. According to their results, contouring, overhang, and scan speed affect the surface roughness significantly. They also showed that the effect of laser power and scanning speed on the overhang surface roughness is clearly more significant than its effect on the opposite free surfaces. In most of the reported roughness values, only one roughness term was presented, while roughness can be measured and reported in several different terms. More information about different roughness measurement methods were delineated by Gadelmawla et al. [37].

Arithmetic average height $\left(R_{a}\right)$ is the most used roughness parameter and is also the mainstream figure of merit used for quality control purposes. It is defined as the average absolute deviation of the roughness irregularities from the mean value over one sampling area. However, this parameter is not sensitive to small variations of the roughness profile. As seen in Fig. 10 , the $R_{a}$ and $R_{q}$ values vary within a short range and the results do not highlight the differences as a function of process parameters. On the other hand, $R_{\mathrm{z}}$ seems to have higher sensitivity, showing a larger variation in the calculated values for each sample. The ten-point height value of $R_{z}$ is more sensitive to occasional high peaks or deep valleys as opposed to $\mathrm{R}_{\mathrm{a}}$, which gives only arithmetic mean values. In other words, high $R_{z}$ values represent the presence of high peaks and valleys on the surface of the material that are cancelled out when the arithmetic mean was calculated for $R_{a}$ values.

Fig. 10a shows that the side surface roughness is influenced by the volumetric energy density as it nearly follows the same trend. However, Fig. 10b suggests that the laser scan strategy has a dominant effect on the surface roughness values rather than the volumetric energy density.

This observation is indeed quite rational since the volumetric energy density brings about a variation in the molten pool size, that affects the side surface, while the laser scan strategy affects the single bead arrays on the top surface. As depicted in Fig. 10b, the island strategy in general creates the lowest $R_{a}, R_{q}$ and $R_{z}$ values. Comparing the $R_{z}$ values for the side and top surfaces, it can be inferred that the top surface is almost twice as rough as the side surface, suggesting that the choice of laser scan strategy should be noted to have a higher influence on the asbuilt surface conditions.

\subsection{Hardness}

Micro-hardness measurements were performed on both horizontal and vertical cross- sections. The average values and the standard deviations are tabulated in Table 6. No significant variation was observed between the different laser scanning strategies employed. However, the hardness values show about $20 \%$ increase for the heat-treated condition compared to the as-built values, representing the evolution of precipitates in the material upon aging.

\subsection{Microstructure}

In this section, the microstructures of the material in the as-built conditions - without and with bed heating - as well as HIPed samples are investigated.

Fig. 11 shows SEM images of the as-built material without bed heating. The images are from the cross-section parallel to the build plate. Fig. 11a shows that the surface of this as-built sample presents severe cracking. The length of these surface cracks lies within a 5-20 $\mu \mathrm{m}$ range. EDS maps (inset images in Fig. 11a) revealed strong signals of Ti- and Al-oxides in the cracks, forming presumably after cracking. Fig. 11b shows microcracks in the bulk material. The majority of these cracks was observed to span in the length of only one laser path, occurring only at the grain boundaries. The EDS results from the micro-cracks in the bulk do not show a similar concentrated distribution of $\mathrm{Al}$ and $\mathrm{Ti}$ elements as observed for the surface cracks. SEM investigations of the etched material revealed that the grain boundaries contain a relatively uniform and continuous phase as shown in Fig. 11c. These phases were investigated in-depth using STEM as presented below. Fig. 11d shows a high magnification image of the matrix. The spherical features are $\gamma^{\prime}$ precipitates revealed by electro-etching. Such type of precipitates within the bulk matrix have been previously reported [4,38-40]. The average size of these precipitates is around $26 \mathrm{~nm}$. Fig. 12 compares the microstructure and crystal orientations of the grains before and after HIPing. In Fig. 12a, the parallel laser tracks are obvious at $45^{\circ}$ angle. The surface area shows evolution of quite fine grains, compared to the bulk sizes. The post-HIPing microstructure in Fig. 12b shows fully recrystallized material and mitigation of strong AM process induced crystal texture. Moreover, abundant twinning boundaries were detected as a result of the HIPing process. The effect of HIPing on crack healing and increasing the relative density of the material was described earlier. The microstructural studies suggest that the HIPing process not only heals the defects, but also improves the isotropic properties in the AM processed $\mathrm{H} 282$ alloy, by removing the dominant crystallographic texture.

Fig. 13 presents SEM images from samples built under bed-heating condition, showing absence of micro-cracks and porosity in the microstructure. The images represent samples that have experienced different laser scanning strategies, and the etching conditions could subsequently vary. One important observation is that the grain boundary phase that was observed in Fig. 11c, is not present in any of the samples processed at a high bed heating temperature. This observation encouraged us to investigate the grain boundary precipitates in detail using STEM. No conspicuous change was recognised by comparing the microstructures evolved under the different laser scanning strategies.

Fig. 14 shows ABF and HAADF STEM images from a selected area including grain boundary precipitates. The material was processed without bed-heating that influences the precipitate evolution. SEM images of this material were presented in Fig. 11. Two regions were investigated separately. They are marked as A* and B* in Fig. 14 and the EDS results are presented in Fig. 15 and Fig. 16 respectively. The objective of the TEM studies is to identify the type and chemistry of the grain boundary precipitate and possibly, determining the formation mechanism.

Table 6

HV hardness data of the samples.

\begin{tabular}{|c|c|c|c|c|}
\hline & Horizontal cross-section (as-built) & Horizontal cross-section (Heat treated) & Vertical cross-section (as-built) & Vertical cross-section (Heat treated) \\
\hline Hardness (HV) & 257 & 305 & 252 & 306 \\
\hline Standard Deviation & 12 & 9 & 7 & 3 \\
\hline
\end{tabular}



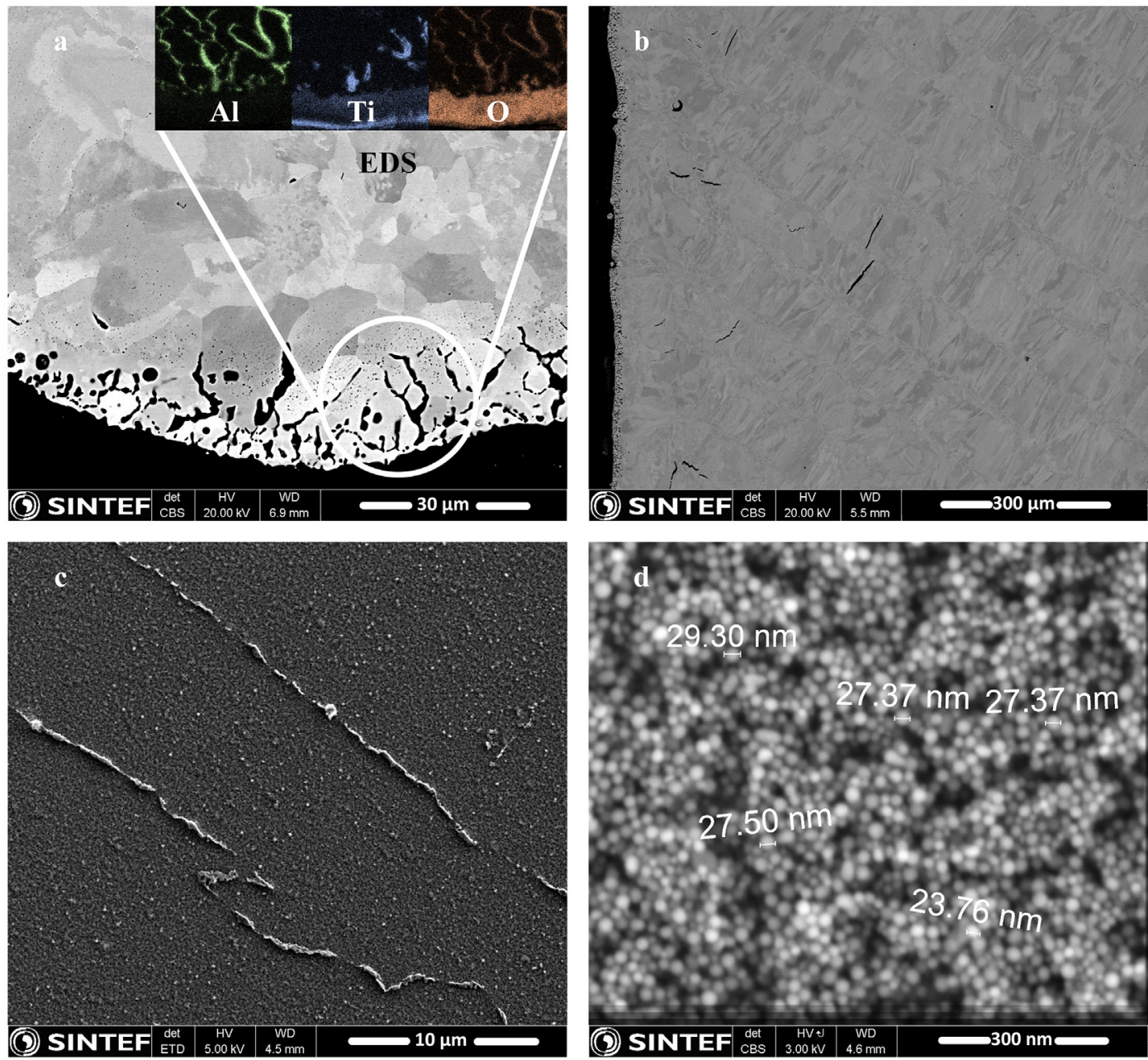

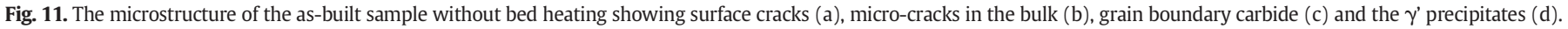
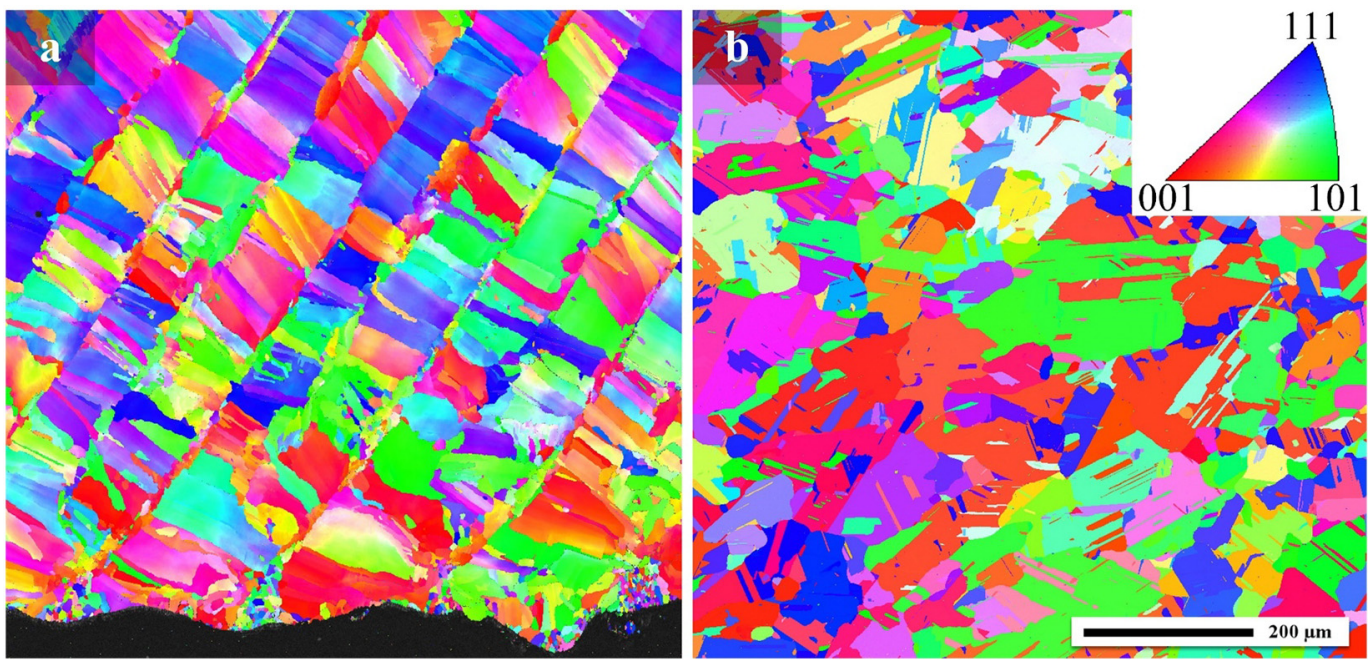

Fig. 12. EBSD IPF-Z maps showing the microstructure in the as built (a) and HIPed (b) conditions. 

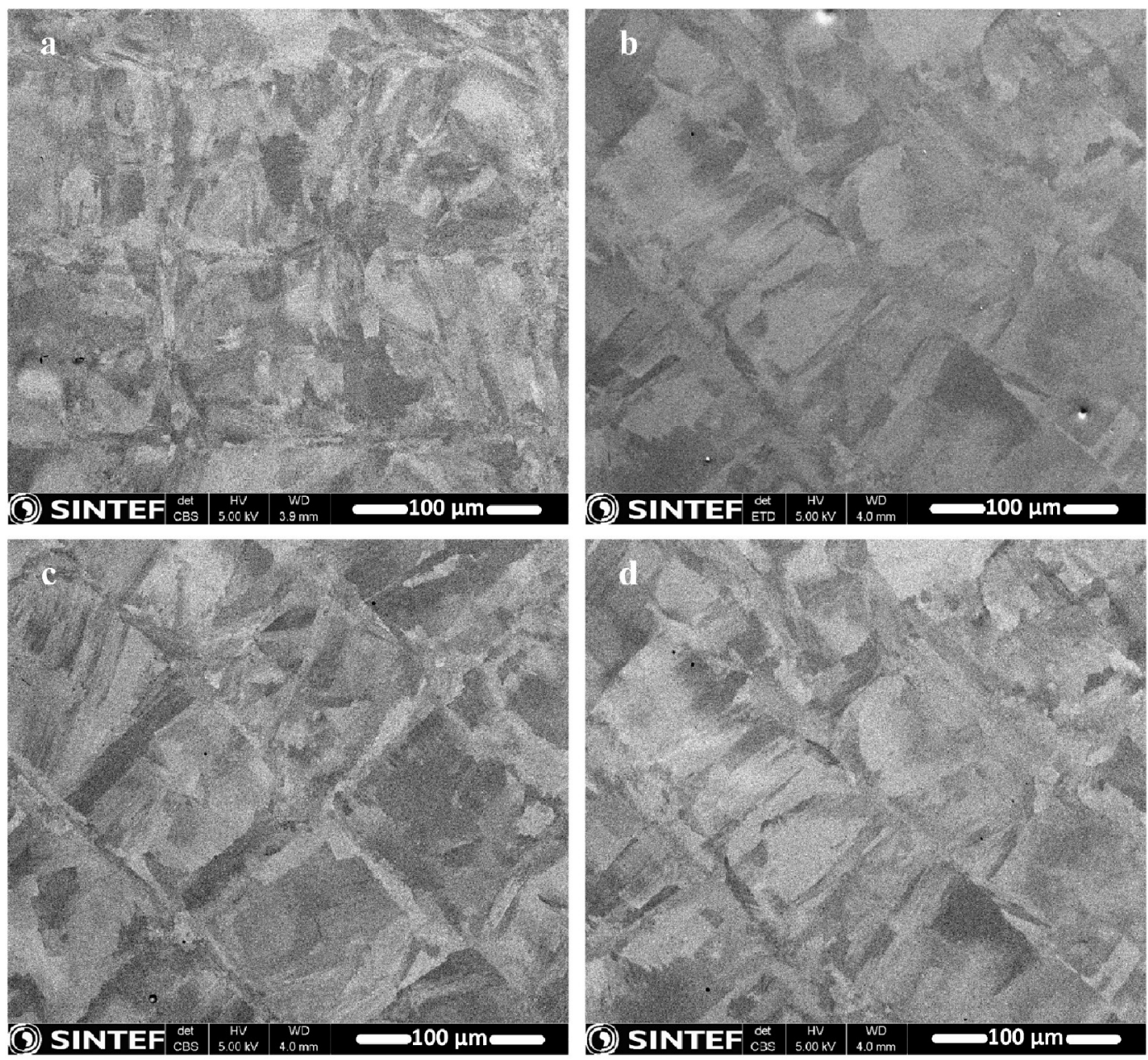

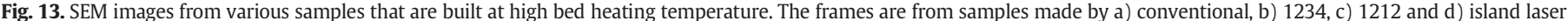
scanning strategies.
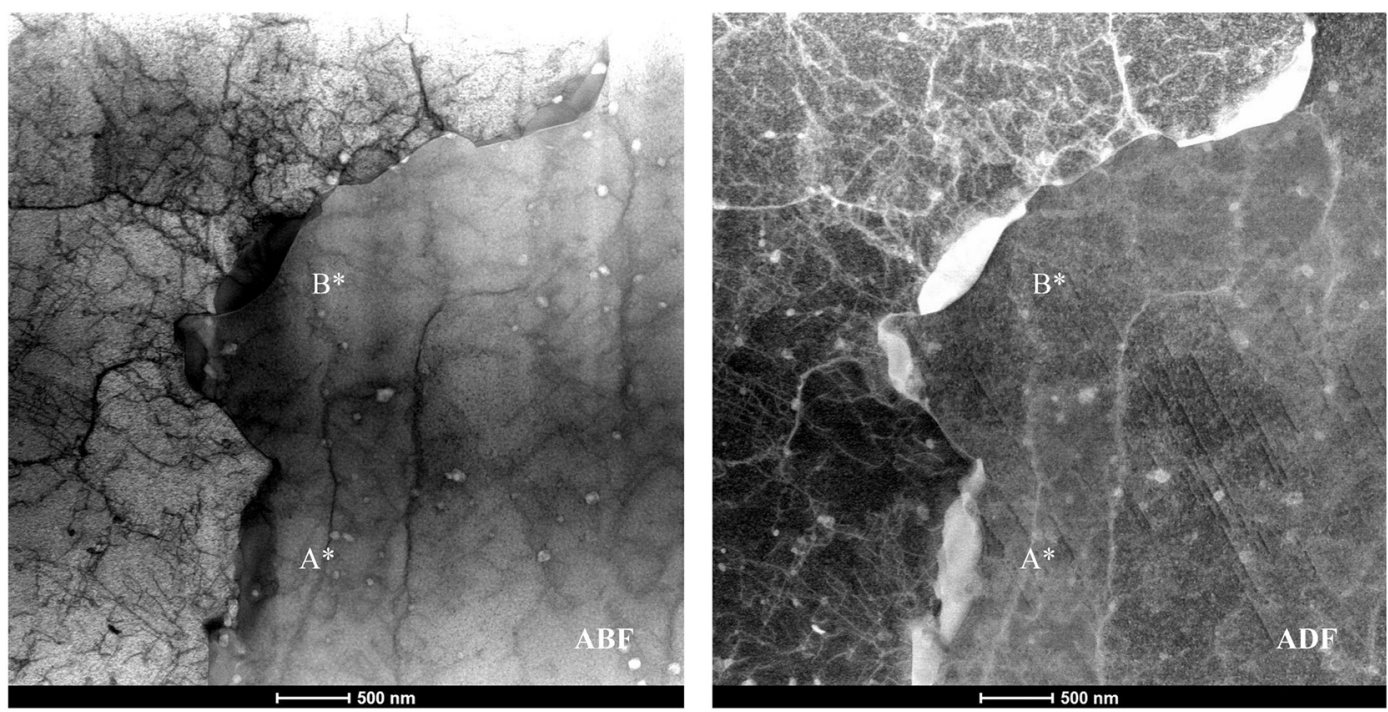

Fig. 14. Annular bright field (ABF) and annular dark field (ADF) images from transmission electron microscopy (TEM) in an arbitrary grain boundary region, showing $A^{*}$ and $B^{*}$ regions of interest. 

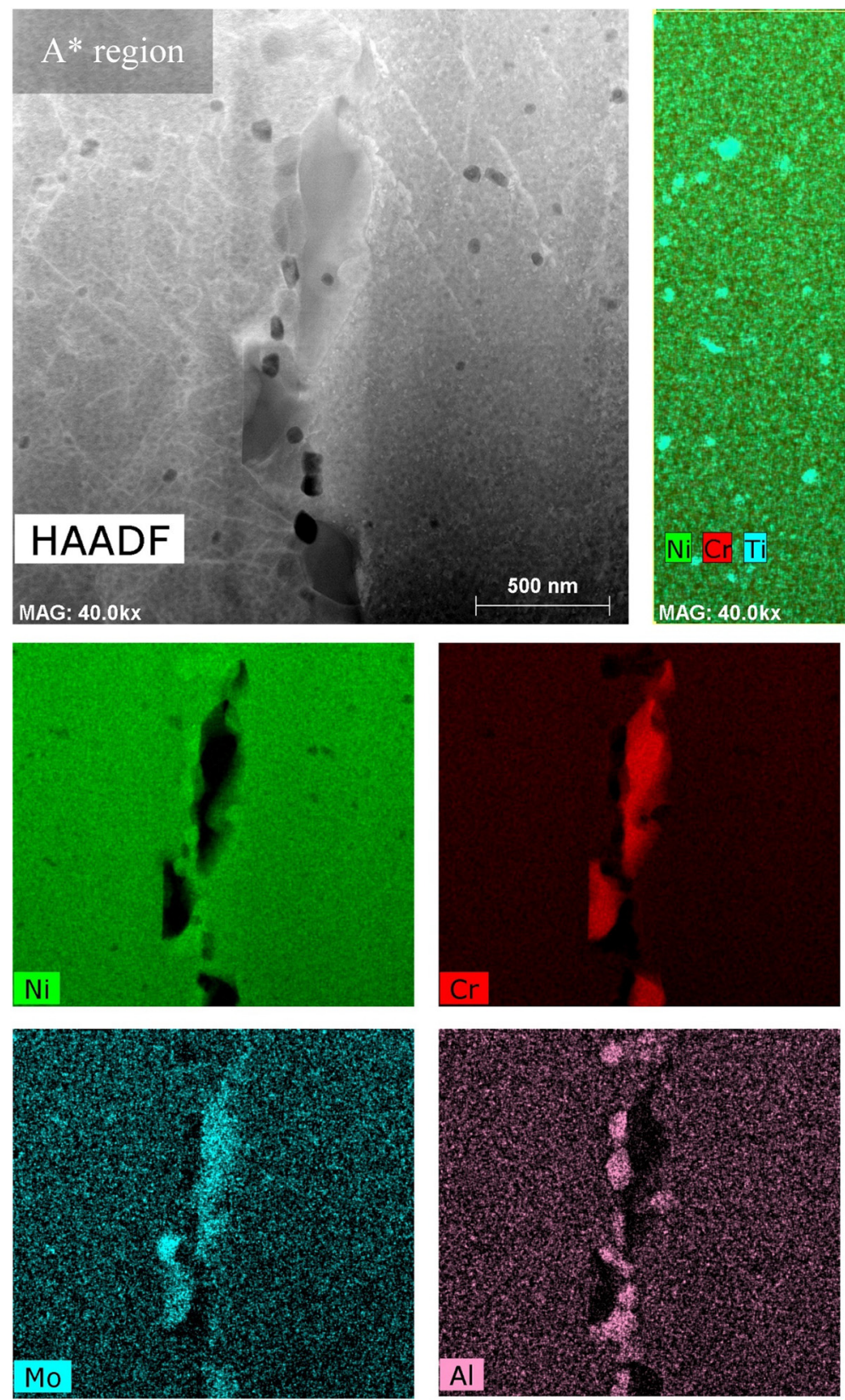
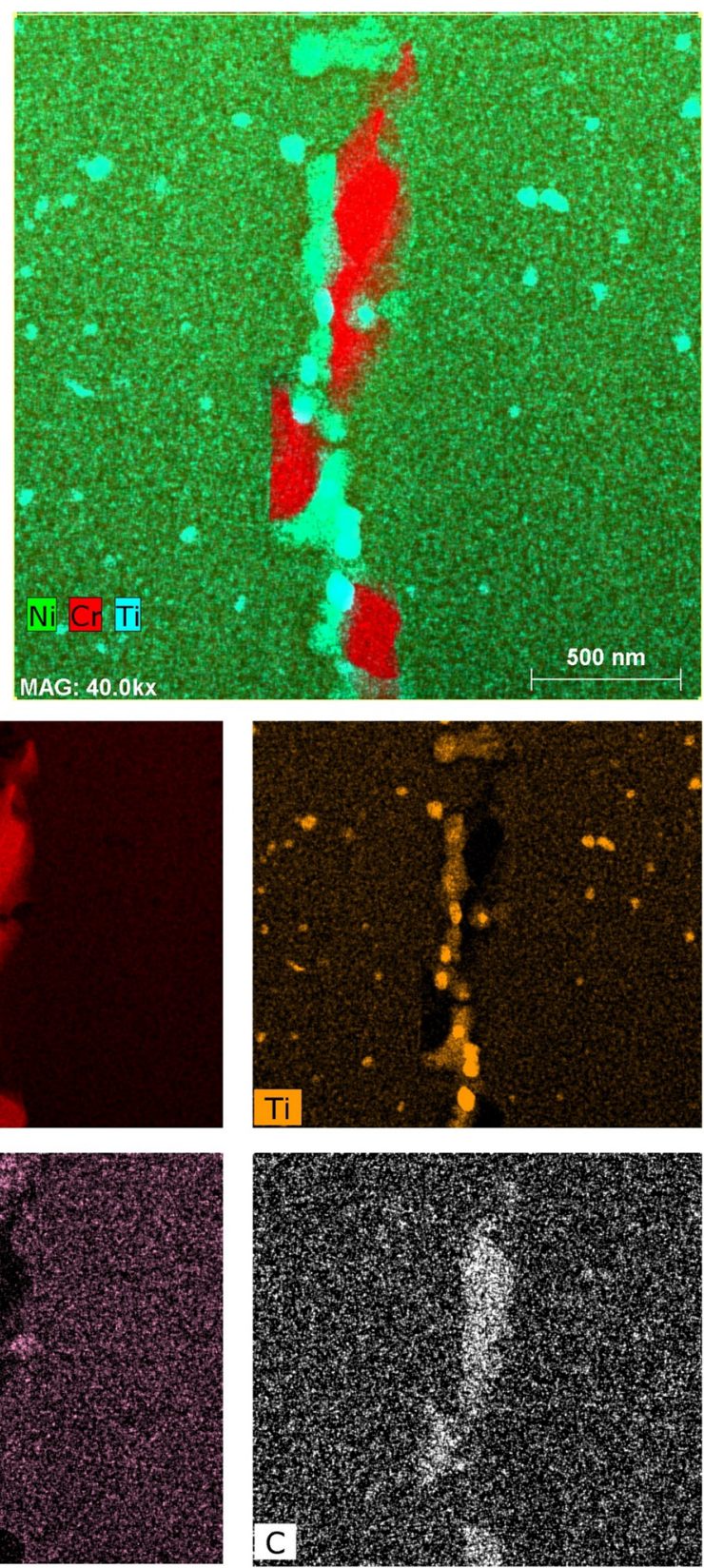

Fig. 15. Energy-dispersive X-ray spectroscopy (EDS) maps of the $A^{*}$ region of interest.

Fig. 15 shows the STEM-EDS results of the $A^{*}$ region. The precipitate is rich in $\mathrm{Cr}$, Mo and C, suggesting a mixed metal carbide. The surrounding grain boundary region shows particles with high concentration of $\mathrm{Ni}$, Ti and $\mathrm{Al}$, the main constituents of the $\gamma^{\prime}\left[\mathrm{Ni}_{3}(\mathrm{Al}, \mathrm{Ti})\right]$ phase. The most compelling observation in the $\mathrm{A}^{*}$ region is that the spatial evolution of $\gamma^{\prime}$ precipitates is influenced by the grain boundary precipitate. Two mechanisms can be hypothesised:

- The $\gamma^{\prime}$ precipitates seem to pile up in the regions where $\mathrm{Cr}$ and Mo are depleted in the matrix. In other words, $\gamma$ ' tends to evolve in the immediate vicinity of the grain boundary precipitate.

- Close periodic lattice match between $\gamma^{\prime}$ and the other two phases makes the $\gamma / \mathrm{M}_{23} \mathrm{C}_{6}$ interface a preferred nucleation site. This argument will be attended later in this section.

Fig. 16 shows STEM-EDS mapping of region $B^{*}$. The type of precipitates and their chemistry agrees with those observed in $A^{*}$. This map supplements the previous region by showing a $\mathrm{M}_{23} \mathrm{C}_{6}$ precipitate cocooned in the $\gamma^{\prime}$ precipitate. The chemistry of the carbide was speculated from the EDS data. This observation suggests that chronologically speaking, the $\mathrm{M}_{23} \mathrm{C}_{6}$ precipitates evolve earlier than $\gamma^{\prime}$ at the grain boundaries.

The precipitates far from the grain boundary show high content of $\mathrm{Ti}$, while depleted in $\mathrm{Ni}$ and $\mathrm{Cr}$. A couple of these precipitates show high carbon content, suggesting titanium carbide chemistry. However, the others could not be identified in a straightforward manner. As it could already be noticed, the oxygen map is not provided in Fig. 15 and Fig. 16. In the EDS technique, the x-ray energy of oxygen $K_{\alpha}$ and chromium $\mathrm{L}_{\alpha}$ overlap, making the deconvolution difficult. Since the material is of high chromium content, the grain boundary precipitates were brought to attention. The determination of the oxygen content is also challenging as the native oxide is present below and above the STEM lamella. Since the Ti rich particles have native oxide at the same level as the matrix no high concentration of oxygen could be verified. 

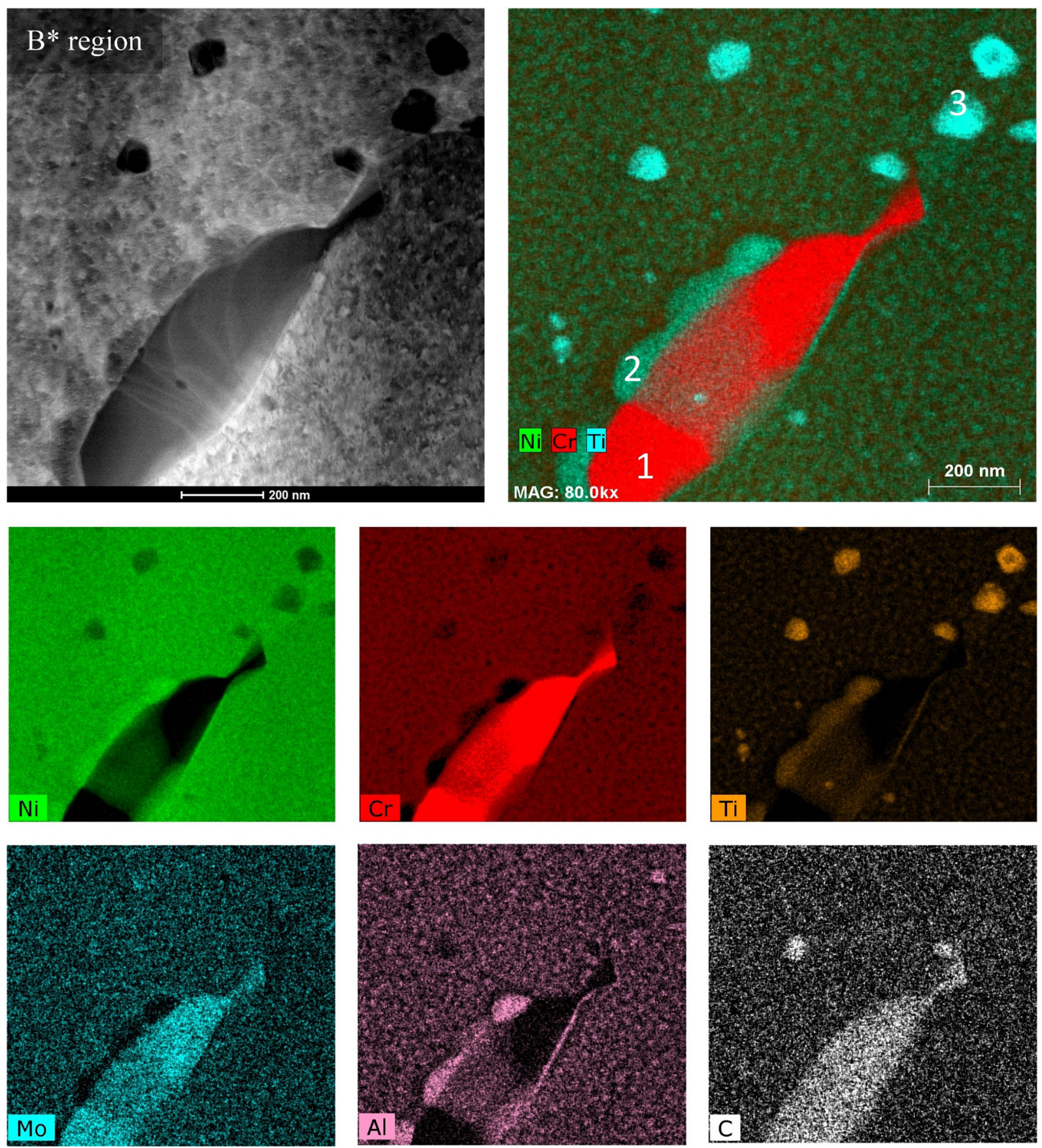

Fig. 16. Energy-dispersive X-ray spectroscopy (EDS) maps of the $B^{*}$ region of interest.

Nonetheless, depletion of $\mathrm{Ni}$ in Ti rich particles away from the grain boundary demonstrates that they are not of $\gamma$ ' type.

An early work by Young et al. [41], on welding of $\mathrm{Ni}-\mathrm{Cr}$ alloys suggested that the ductility-dip cracking phenomenon is associated with the mixed metal carbides in the grain boundary. Our observation from the TEM-EDS results implies that $\mathrm{M}_{23} \mathrm{C}_{6}$ precipitates are rich in $\mathrm{Cr}$ and Mo. Therefore, the chemical composition of these precipitates is probably similar to the stable $\mathrm{Cr}_{21}\left(\mathrm{MoC}_{3}\right)_{2}$ stoichiometry [42]. This has been confirmed by the atomic resolution imaging and diffraction on the particle. Fig. 17 illustrates the atomic resolution images of the crystal structure of the mixed metal carbide. As it can be seen, the observed and simulated results are in good agreement. Table 7 lists the crystal structure of each phase.
As shown in Fig. 18, the orientation relationship between matrix $(\gamma)$, precipitate $\left(\gamma^{\prime}\right)$, and grain boundary carbide $\left(\mathrm{Cr}_{21}\left(\mathrm{MoC}_{3}\right)_{2}\right)$ is cube-oncube with fully coherent interfaces.

Referring to Table 7, the lattice constants of $\gamma$ and $\gamma^{\prime}$ are approximately 3 times smaller than that of $\mathrm{Cr}_{21}\left(\mathrm{MoC}_{3}\right)_{2}$, while the constants for $\gamma$ and $\gamma^{\prime}$ are similar. This has been shown and confirmed in Fig. $18 \mathrm{~b}$ and c. The lattice mismatch between $3 \times \gamma$ and $\mathrm{Cr}_{21}\left(\mathrm{MoC}_{3}\right)_{2}$ is somewhat larger than the mismatch between $3 \times \gamma^{\prime}$ and $\mathrm{Cr}_{21}\left(\mathrm{MoC}_{3}\right)_{2}$. This is due to the fact that the lattice constant of $\gamma^{\prime}$ is slightly smaller than $\gamma$, accommodating for lower interface energy next to the $\mathrm{Cr}_{21}$ $\left(\mathrm{MoC}_{3}\right)_{2}$ precipitates. The chronological evolution of the phases that was discussed previously suggest that $\gamma-\mathrm{Cr}_{21}\left(\mathrm{MoC}_{3}\right)_{2}$ interface settles prior to precipitation of $\gamma^{\prime}$. As scrutinized above, interface between $\mathrm{Cr}_{21}$ 

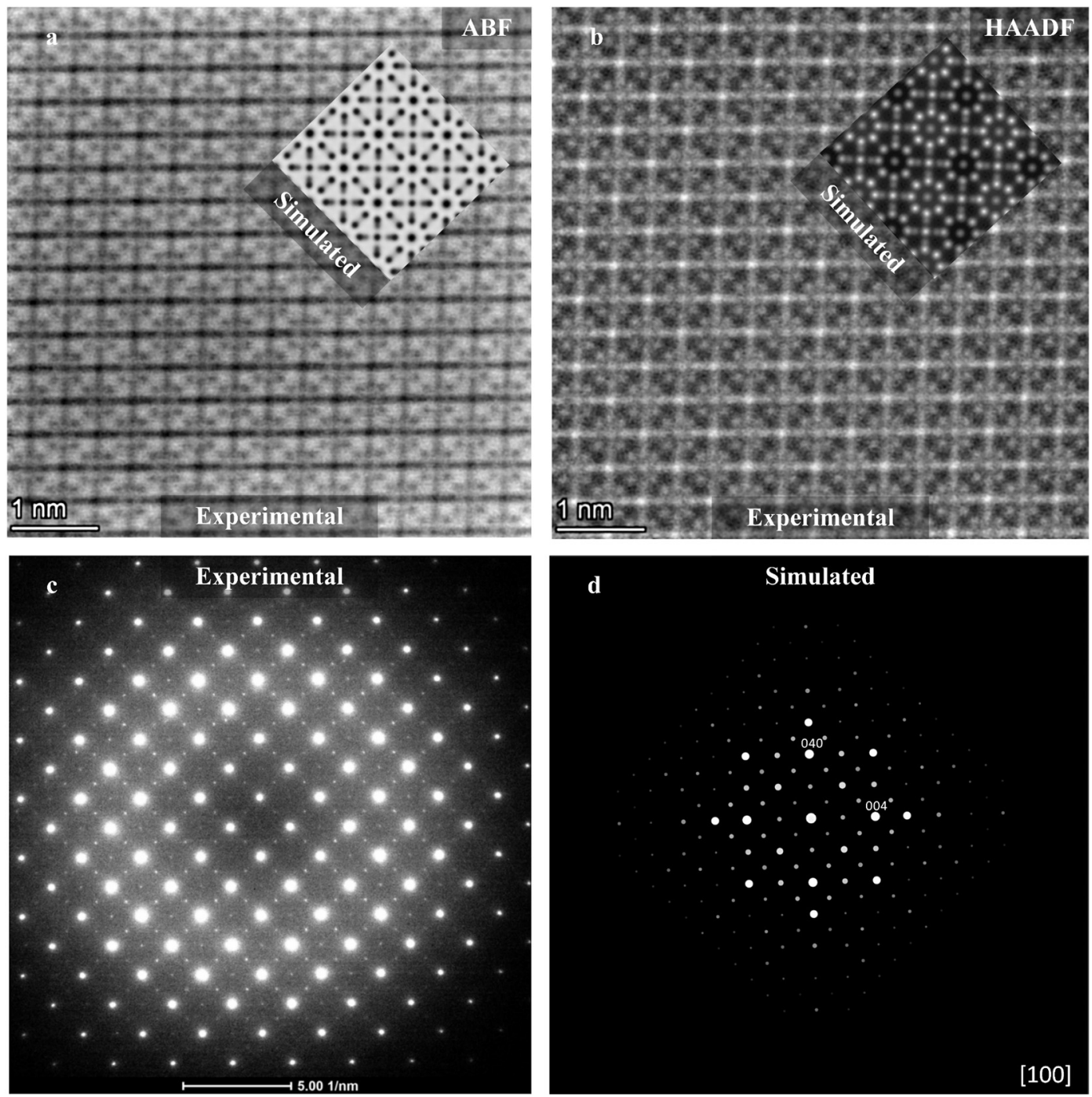

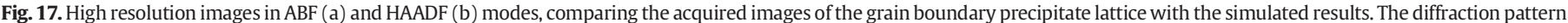
of the $\mathrm{M}_{23} \mathrm{C}_{6}$ precipitates are also shown in experimental (c) and simulated (d) frames.

$\left(\mathrm{MoC}_{3}\right)_{2}$ and the matrix becomes preferred sites for precipitation of $\gamma^{\prime}$. Therefore, $\gamma^{\prime}$ structure may surround the grain boundary carbide. This agrees with the reported observations in Fig. 15 and Fig. 16. Nevertheless, the expected mismatch between the phases is likely to induce stress at the fully coherent interfaces, which become favoured nucleation sites for micros-cracks during the recursive thermal cycles typical of AM processing.

Fig. 18d schematically illustrates how the three crystal structures sit next to each other with small lattice mismatch. The magnitude of this mismatch defines the strengthening mechanism in the alloy and the phenomenon has been the topic of research in numerous studies. It is a known fact that the type of grain boundary, cooling rate and aging temperature (or subsequent thermal cycles in case of AM) influence the evolution and precipitation of grain boundary carbides. The combined findings in this study suggest that cracking occurs when the stress variation across a grain boundary is high. As shown previously, no- or very little grain boundary carbide was present when keeping the build temperature at $300^{\circ} \mathrm{C}$, meaning that the interface between the carbide and the matrix is the weakest link. The selected temperature was far less than the carbide dissolution temperature [45]. However, earlier findings by Blavette et al. [46], suggest that the formation of grain boundary carbide is purely driven by the segregation at high cooling rates. Higher bed heating slows down the cooling rate, yet the selected temperature is not high enough to accelerate formation and growth of $\gamma^{\prime}$ precipitates.

Table 7

Room temperature lattice parameters of $\gamma$ and $\gamma^{\prime}$ phases $\left({ }^{1}\right)$ from theoretical calculations.

\begin{tabular}{|c|c|c|c|c|}
\hline Phase & Crystal structure & Space group & Lattice constant @RT & Lattice constant @RT ${ }^{1}$ \\
\hline$\gamma$ & $f c c$ & Fm-3 m (225) & $\mathrm{a}_{0}=3.65 \AA[43]$ & $\mathrm{a}_{0}=3.5852 \AA$ \\
\hline$\gamma^{\prime}$ & $f c c\left(L 1_{2}\right)$ & $\mathrm{Pm}-3 \mathrm{~m}(221)$ & $\mathrm{a}_{0}=3.63 \AA$ [39] & $\mathrm{a}_{0}=3.5843 \AA$ \\
\hline $\mathrm{Cr}_{21}\left(\mathrm{MoC}_{3}\right)_{2}$ & $f c c$ & Fm-3 m (225) & $\mathrm{a}_{0}=10.65 \AA$ [42] & $\mathrm{a}_{0}=10.64387 \AA[44]$ \\
\hline
\end{tabular}



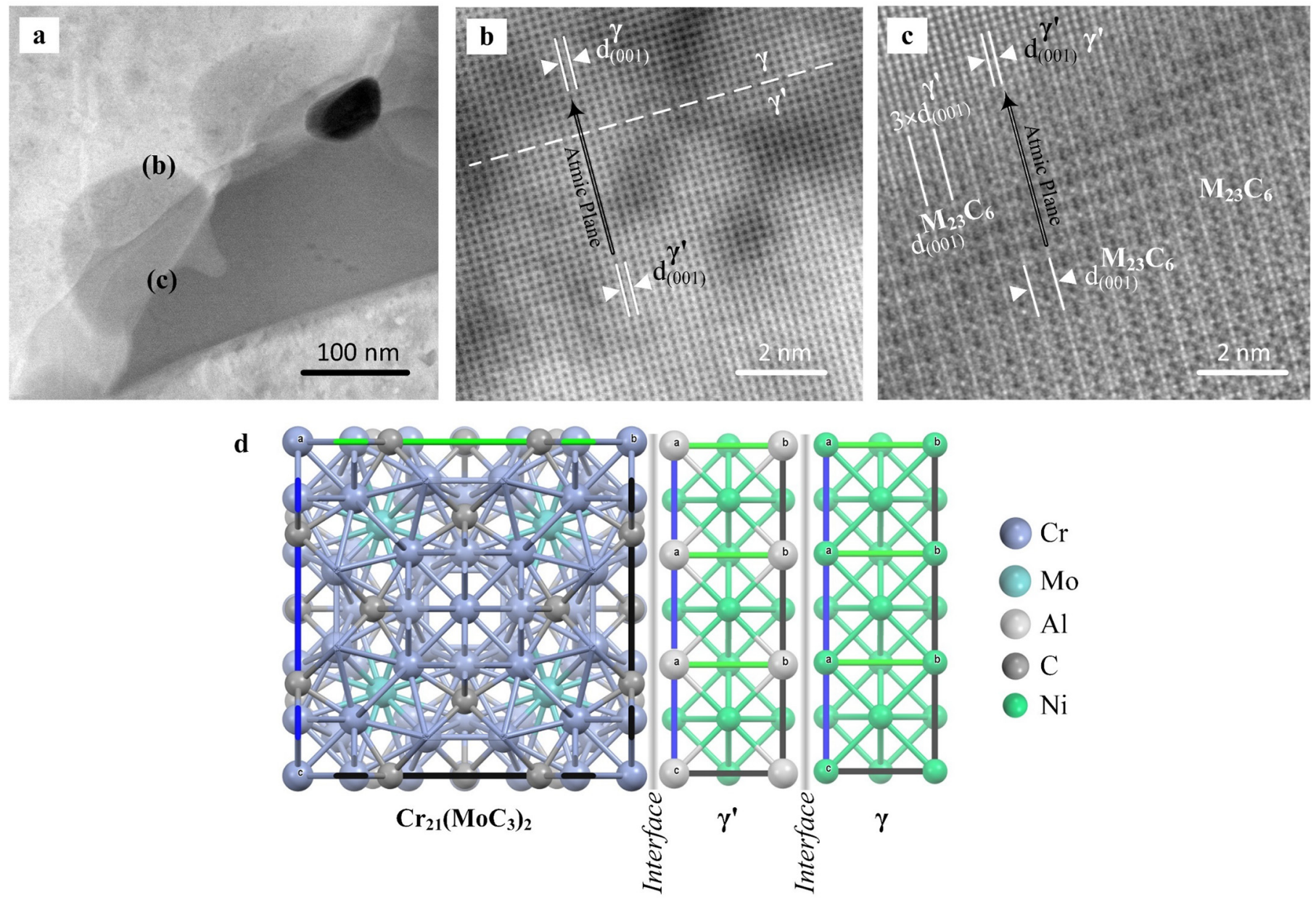

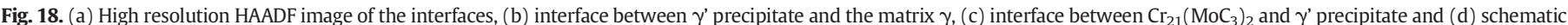
illustration of the three phases side-by-side. The provided graphical lattices are in equal scales, showing mismatch and alignment of atomic planes.

\section{Conclusions}

A study on PBF-LB processing of $\mathrm{H} 282$ was conducted successfully. It consists of stepwise parameter studies, variation of build plate heating, innovative scanning strategies and the manufacturing of several cubic samples. Those samples were characterized for their microstructural features including defects, precipitates, hardness, and surface roughness. The following can be concluded:

- Processing the material without build plate heating generated extensive grain boundary cracking and high porosity in all cases. Although the amount and array of the micro-cracks depend on the scanning strategy, they were observed in all samples.

- The additively manufactured H282 showed an increased hardness in the as-built state compared to the traditionally solution-annealed material. Solution annealing followed by age hardening was applied to the samples using standard heat treatment procedure. The heattreated samples displayed similar hardness as traditional agehardened plate-material.

- Surface roughness of the samples was affected by the process parameters on the side surfaces and by the scanning strategy on the top surface of the material.

- HIP of the alloy causes recrystallization of the microstructure and crack healing. The HIPed samples show an increase in the relative density to as much as $99.98 \%$.

- Applying $300{ }^{\circ} \mathrm{C}$ heating to the build platform during manufacturing resolves the grain boundary cracking issue and increased the density of the samples. One of the special build strategies, named 1234 , achieved a density of 99,87\% under elevated bed temperature.

- The evolution of $\mathrm{M}_{32} \mathrm{C}_{6}$ carbide and accumulation of $\gamma^{\prime}$ on the grain boundaries make them susceptible to cracking, especially on the boundaries across which high gradient of residual stresses is developed. According to the crystal elasticity simulations, these stresses emerge due to the anisotropic properties of the matrix at individual grain level.

- The grain boundary precipitates are of $\gamma^{\prime}$ and $\mathrm{Cr}_{21}\left(\mathrm{MoC}_{3}\right)_{2}$ types. The carbide seems to be evolving chronologically earlier than the $\gamma$ '.

- No grain boundary precipitates were observed in the samples processed at high build temperature.

It has been proven that crack-free $\mathrm{H} 282$ can be processed by PBF-LB technology. However, without build plate heating during manufacturing, no progress could be made towards mitigating cracking. The comprehensive approach to the problem through processing, modelling and advanced characterization standpoints was the key to understanding the underlaying cracking mechanism. The generated knowledge resulted in selecting proper AM process parameters for this alloy.

\section{Data availability}

The raw data required to reproduce these findings cannot be shared at this time as the data also form part of an ongoing study. The CAE 
model that is developed in Abaqus can be shared upon request. The interested readers are encouraged to take direct contact to the authors of this article for more information.

\section{Declaration of Competing Interest}

The authors declare that there are no conflicts of interest on the subject matter or materials discussed in this manuscript.

\section{Acknowledgement}

The funding for completion of this work was provided by MKRAM (IPN, Research Council of Norway, grant no. 248243) and HighAM (SINTEF's internal strategic funding scheme) projects. MKRAM's partner GKN Aerospace Norway's interest in $\mathrm{H} 282$ was the main motivation for in-depth investigation of this material and their support is deeply acknowledged. The authors would like to thank Dr. Irma Heikkilä at the department of Powder Materials and Additive Manufacturing, SWERIM AB, Sweden, for facilitating the HIPing process of the H282 samples.

\section{References}

[1] ISO/ASTM52900, Standard Terminology for Additive Manufacturing - General Principles - Terminology, 2015

[2] K. Unocic, M. Kirka, E. Cakmak, D. Greeley, A. Okello, S. Dryepondt, Evaluation of additive electron beam melting of Haynes 282 alloy, Mater. Sci. Eng. A 772 (2020) 138607.

[3] M.M. Kirka, K.A. Unocic, K. Kruger, A. Forsythe, Process Development for Haynes ${ }^{\circledR}$ 282® Using Additive Manufacturing, Oak Ridge National Lab.(ORNL), Oak Ridge, TN (United States), 2018

[4] A. Ramakrishnan, G. Dinda, Microstructure and mechanical properties of direct laser metal deposited Haynes 282 superalloy, Mater. Sci. Eng. A 748 (2019) 347-356.

[5] A. Deshpande, S.D. Nath, S. Atre, K. Hsu, Effect of post processing heat treatment routes on microstructure and mechanical property evolution of haynes $282 \mathrm{Ni}$ based superalloy fabricated with selective laser melting (SLM), Metals 10 (5) (2020) 629.

[6] R. Otto, V. Brøtan, A.S. Azar, O. Åsebø, Processing of Haynes® $282 ®$ Alloy by Laser Powder Bed Fusion Technology, TMS 2019 148th Annual Meeting \& Exhibition Supplemental Proceedings, Springer, 2019 503-510.

[7] O. Adegoke, J. Andersson, H. Brodin, R. Pederson, Review of laser powder bed fusion of gamma-prime-strengthened nickel-based Superalloys, Metals 10 (8) (2020) 996.

[8] M.J. Donachie, S.J. Donachie, Superalloys: A Technical Guide, ASM international, 2002.

[9] A. Ramirez, J. Lippold, High temperature behavior of Ni-base weld metal: part IIinsight into the mechanism for ductility dip cracking, Mater. Sci. Eng. A 380 (1-2) (2004) 245-258.

[10] A.P. Mouritz, Introduction to Aerospace Materials, 2012 251-267.

[11] R.C. Reed, The Superalloys: Fundamentals and Applications, Cambridge university press, 2008.

[12] F.C. Campbell, Elements of Metallurgy and Engineering Alloys, 2008 563-578.

[13] G. Brunetti, A. Settefrati, A. Hazotte, S. Denis, J.J. Fundenberger, A. Tidu, E. Bouzy, Determination of gamma-gamma' lattice misfit in a single-crystal nickel-based superalloy using convergent beam electron diffraction aided by finite element calculations, Micron 43 (2-3) (2012) 396-406.

[14] H.T. Kim, S.S. Chun, X.X. Yao, Y. Fang, J. Choi, Gamma prime $\left(\gamma^{\prime}\right)$ Precipitating and Ageing Behaviours in Two Newly Developed Nickel-Base Superalloys, 1997.

[15] L.M. Pike, Development of a Fabricable Gamma-Prime $\left(\gamma^{\prime}\right)$ Strengthened Superalloy, 2008.

[16] G.N. Maniar, J.J.E. Bridge, H.M. James, G.B. Heydt, Correlation of gamma-gamma prime mismatch and strengthening in NiFe-Ni base alloys containing aluminum and titani, 1970

[17] C. Qiu, H. Chen, Q. Liu, S. Yue, H. Wang, On the solidification behaviour and cracking origin of a nickel-based superalloy during selective laser melting, Mater. Charact. 148 (2019) 330-344.
[18] L.O. Osoba, A Study on Laser Weldability Improvement of Newly Developed Haynes 282 Superalloy, 2012.

[19] L.O. Osoba, R.G. Ding, O.A. Ojo, Improved resistance to laser weld heat-affected zone microfissuring in a newly developed superalloy HAYNES 282, Metall. Mater. Trans. A 43 (11) (2021)

[20] L.O. Osoba, R.G. Ding, O.A. Ojo, Microstructural analysis of laser weld fusion zone in Haynes 282 superalloy, Mater. Charact. (2012) 93-99.

[21] L.O. Osoba, O.A. Ojo, Influence of laser welding heat input on HAZ cracking in newly developed Haynes 282 superalloy, Mater. Sci. Technol. 28 (4) (2012) 431-436.

[22] J.L. Caron, Weldability and Welding Metallurgy of Haynes 282 Alloy, 8th International Symposium on Superalloy 718 and Derivatives, 2014.

[23] F. Hanning, J. Andersson, Weldability of wrought Haynes® $282 ®$ repair welded using manual gas tungsten arc welding, Welding World 62 (1) (2017) 39-45.

[24] J. J, A.J. B, A.H. H, Weldability of Ni-based superalloys Waspaloy ${ }^{\circledR}$ and Haynes ${ }^{\circledR}$ $282 \AA$ - A study performed with varestraint testing, research \& reviews, J. Mater. Sci. 04 (04) (2016).

[25] H. White, M. Santella, E.D. Specht, Weldability of HAYNES 282 alloy for new fabrications and after service exposure, Ener. Mater. 4 (2) (2013) 84-91.

[26] J. Caron, L. Pike, Weldability of HAYNES 282 Superalloy after Long-Term Thermal Exposure, MATEC Web of Conferences 14, 2014

[27] L. Osoba, O. Ojo, Influence of laser welding heat input on HAZ cracking in newly developed Haynes 282 superalloy, Mater Sci Tech-Lond 28 (4) (2012) 431-436.

[28] N. Sobczak, P. Zenon, R. Purgert, W. Uhl, Castability of HAYNES 282 Alloy, 2012.

[29] K. Amato, S. Gaytan, L.E. Murr, E. Martinez, P. Shindo, J. Hernandez, S. Collins, F. Medina, Microstructures and mechanical behavior of Inconel 718 fabricated by selective laser melting, Acta Mater. 60 (5) (2012) 2229-2239.

[30] P.P. Vijay, N. Patil, Gray scale image segmentation using OTSU Thresholding optimal approach, J. For. Res. 2 (05) (2016).

[31] O. Hubert, X. Milhet, P. Gadaud, M. Tatat, P.-O. Renault, C. Coupeau, Modeling of Young' s modulus variations with temperature of $\mathrm{Ni}$ and oxidized $\mathrm{Ni}$ using a magneto-mechanical approach, Mater. Sci. Eng. A 633 (2015) 76-91.

[32] C. Kumara, D. Deng, J. Moverare, P. Nylén, Modelling of anisotropic elastic properties in alloy 718 built by electron beam melting, Mater Sci Tech-Lond 34 (5) (2018) 529-537.

[33] D. Siebörger, H. Knake, U. Glatzel, Temperature dependence of the elastic moduli of the nickel-base superalloy CMSX-4 and its isolated phases, Mater. Sci. Eng. A 298 (1-2) (2001) 26-33.

[34] M.M. Nor, N. Ma'at, C. Ho, An anisotropic elastoplastic constitutive formulation generalised for orthotropic materials, Contin. Mech. Thermodyn. 30 (4) (2018) 825-860.

[35] P. Wang, W.J. Sin, M.L.S. Nai, J. Wei, Effects of processing parameters on surface roughness of additive manufactured Ti- $6 \mathrm{Al}-4 \mathrm{~V}$ via electron beam melting, Materials 10 (10) (2017) 1121.

[36] Y. Tian, D. Tomus, P. Rometsch, X. Wu, Influences of processing parameters on surface roughness of Hastelloy X produced by selective laser melting, Add. Manufact. 13 (2017) 103-112.

[37] E. Gadelmawla, M. Koura, T. Maksoud, I. Elewa, H. Soliman, Roughness parameters, J. Mater. Process. Technol. 123 (1) (2002) 133-145.

[38] C. Joseph, C. Persson, M.H. Colliander, Influence of heat treatment on the microstructure and tensile properties of Ni-base superalloy Haynes 282, Mater. Sci. Eng. A 679 (2017) 520-530.

[39] C. Joseph, Microstructure Evolution and Mechanical Properties of Haynes 282, Chalmers University of Technology, 2018.

[40] L. Pike, Development of a fabricable gamma-prime ( $\left.\gamma^{\prime}\right)$ strengthened superalloy, Superalloys 2008 (2008) 191-200.

[41] G. Young, T. Capobianco, M. Penik, B. Morris, J. McGee, The mechanism of ductility dip cracking in nickel-chromium alloys, Welding J.New York 87 (2) (2008) 31.

[42] A. Bowman, G. Arnold, E. Storms, N. Nereson, The crystal structure of Cr23C6, Acta Crystallograph. Sec B 28 (10) (1972) 3102-3103.

[43] Ł. Rakoczy, O. Milkovič, B. Rutkowski, R. Cygan, M. Grudzień-Rakoczy, F. Kromka, A. Zielińska-Lipiec, Characterization of $\gamma^{\prime}$ Precipitates in cast Ni-based Superalloy and their behaviour at high-homologous temperatures studied by TEM and in situ XRD, Materials 13 (10) (2020) 2397.

[44] K. Persson, Materials data on Cr21(MoC3)2 (SG:225) by materials project, M. Project (Ed.) Materials Project, 2016.

[45] P. Berthod, C. Vébert, L. Aranda, R. Podor, C. Rapin, Study of carbide transformations during high-temperature oxidation of nickel-base superalloys, Oxid. Met. 63 (1-2) (2005) 57-72.

[46] D. Blavette, P. Duval, L. Letellier, M. Guttmann, Atomic-scale APFIM and TEM investigation of grain boundary microchemistry in Astroloy nickel base superalloys, Acta Mater. 44 (12) (1996) 4995-5005. 